\title{
Lower mantle material properties and convection models of multiscale plumes
}

\section{Ctirad Matyska}

Department of Geophysics, Faculty of Mathematics and Physics, Charles University, V Holešovičkách 2, 18000 Praha 8, Czech Republic

\section{David A. Yuen}

Department of Geology and Geophysics and Minnesota Supercomputing Institute, University of Minnesota, Minneapolis, MN 55455-0219, U.S.A.

\begin{abstract}
We present the results of numerical mantle convection models demonstrating that dynamical effects induced by variable mantle viscosity, depth-dependent thermal expansivity, radiative thermal conductivity at the base of the mantle, the spinel to perovskite phase change and the perovskite to post-perovskite phase transition in the deep mantle can result in multiscale mantle plumes: stable lower-mantle superplumes are followed by groups of small upper-mantle plumes. Both radiative thermal conductivity at the base of the lower-mantle and a strongly decreasing thermal expansivity of perovskite in the lower-mantle can help to induce partially layered convection with intense shear heating under the transition zone, which creates a low viscosity zone and allow for the production of secondary mantle plumes emanating from this zone. Large-scale upwellings in the lower-mantle, which are induced mainly by both the style of lower-mantle viscosity stratification and decrease of thermal expansivity, control position of central upper-mantle plumes of each group as well as the upper-mantle plume-plume interactions.
\end{abstract}

\section{Keywords}

Partially layered convection, shear heating, temperature- and pressure-dependent viscosity, depth-dependent thermal expansivity, post-perovskite phase transition, radiative heat transfer in D".

\section{INTRODUCTION}

During the last decades, geophysicists have pondered over the causes and consequences of surface hotspots within the framework of plate tectonics. Morgan (1971) developed the seminal idea of thin plumes emanating from the core-mantle boundary and their rapid passage to the surface. Such an mechanism corresponds to some burgeoning fluid-dynamical ideas of boundary-layer instabilities and their finite-amplitude growth to diapirs and thin vertical upwellings, (Howard, 1964; Goldstein et al., 1990). The catalogues of surface hotspots (e.g. Burke and Wilson, 1976) were compiled in the 1970s and since then it has been recognized that some of the hotspots might have origins from the transition zone (Allegre and Turcotte, 1985) or from continental edges via small-scale convection in the upper-mantle (King and Anderson, 1995). The secondary instabilities from the transition zone were modelled successfully in the 1990s by Honda et al. (1993), Steinbach and Yuen (1994) and Cserepes and Yuen (1997), who showed the importance of high-enough resolution in the transition zone in capturing these 
thinner plumes with a width of around $50 \mathrm{~km}$. Courtillot et al. (2003) also consider the population of hotspots over the Earth's surface should have their origins in different depths. This idea is also supported by recent seismic imaging by Zhao (2004) and Montelli et al. (2004). Implicit in this type of reasoning is the assumption of a relatively stationary state of mantle convection occurring today.

In the lower-mantle large structures with low seismic velocities were found under Africa and the central Pacific by Dziewonski's pioneering work (Dziewonski, 1984; Su and Dziewonski, 1991) exhibiting axial symmetry (Matyska, 1995) and corresponding to the longwavelengths geoid anomalies and two geographical groups of surface hotspots (e.g. Crough and Jurdy, 1980; Stefanick and Jurdy, 1984; Richards and Hager, 1988; Matyska et al., 1998). These lower-mantle structures were called superplumes and recognized by Maruyama (1994) as a latestage development of mantle evolution. They should be joined with the secondary smaller plumes generated at the boundary between the lower- and the upper-mantle at $670 \mathrm{~km}$ depth.

The basic physics of heat transfer in the Earth's mantle can be critically dependent on various combinations of mantle properties. We would like to emphasize that this physics is nonlinear and thus one cannot estimate at all the effects of some material changes a priori without carrying out numerical experiments. The main purpose of our paper is to point out that the multiscale nature of mantle plumes in numerical models is a consequence of the richness and complexity of mantle physical properties and processes, such as phase transitions in both the upper- and deep-mantle. We will demonstrate this point by showing some illustrative examples, drawn from both simple and complex models in the long-time regime of mantle convection. One cannot obtain a scenario of multiscale plumes, using a simple physical model. Simple steadystate models without phase transitions may work to some degrees in the upper-mantle but still they would have problems explaining volcanoes associated with subducting slabs, which require thermal-chemical Rayleigh-Taylor instabilities (Gerya and Yuen, 2003) or secondary convective instabilities (Honda et al., 2002).

Although thermal-chemical convection has long been recognized as being an integral component of mantle convection (Hansen and Yuen, 1989, 1994; Tackley, 1998; Nakagawa and Tackley, 2005; Tan and Gurnis, 2005), we will restrict ourselves to the use of thermal convection. Our purely thermal models will have the following geophysical attributes: (1.) phase transitions both at the depth of $670 \mathrm{~km}$ and in the lower-mantle (Iitaka et al., 2004; Murakami et al., 2004; Oganov and Ono, 2004; Tsuchiya et al., 2004), (2.) radiative thermal conductivity in the lower-mantle (Lubimova, 1958; Matyska et al., 1994; van den Berg et al., 2002; Matyska and Yuen, 2005, 2006), (3.) temperature- and depth-dependent viscosity, where the depth-dependent viscosity has a peak in the mid-lower-mantle (Mitrovica and Forte, 2004), (4.) depth-dependent thermal coefficient of expansion (Chopelas and Boehler, 1992; Katsura et al., 2005), (5.) nonlinear feedback effects, such as viscous dissipation and its coupling to temperature-dependent viscosity. Other effects, not considered here, but which are nonetheless very important, are nonNewtonian rheology (e.g. Larsen and Yuen, 1997), grain-size dependent rheology (Solomatov, 1996, 2001; Korenaga, 2005) and grain-size dependent thermal conductivity (Hofmeister, 2005).

\section{MODEL DESCRIPTION AND THEORETICAL BACKGROUND}

The fundamental laws of conservation describing transfer of heat in a dynamic Earth under the fluid approximation together with rheological behavior and an equation of state are (for details see the electronic lecture notes displayed on the web page 
http://geo.mff.cuni.cz/ cm/geoterm.pdf ;

see also the monographs, e.g., by Ranalli (1995) and Schubert et al. (2001)):

Equation of continuity (conservation of mass)

$$
\frac{\partial \rho}{\partial t}+\nabla \cdot(\rho \boldsymbol{v})=0
$$

where $\rho$ is the density, $\boldsymbol{v}$ is the velocity of motion and $t$ is the time. The symbol $\nabla$ denotes the nabla operator and the dot $\cdot$ is the scalar product.

Momentum equation (in a non-rotating Earth model)

$$
\nabla \cdot \tau+\rho \boldsymbol{g}=\rho \frac{\partial \boldsymbol{v}}{\partial t}+\rho \boldsymbol{v} \cdot \nabla \boldsymbol{v}
$$

where $\tau$ is the Cauchy stress tensor and $\boldsymbol{g}$ is the gravity acceleration.

Conservation of moment of momentum

$$
\tau=(\tau)^{T}
$$

where ${ }^{T}$ denotes transpose of a matrix.

Rheological relationship

$$
\tau=-p \boldsymbol{I}+\boldsymbol{\sigma}(\boldsymbol{v}), \quad \lim _{\boldsymbol{v} \rightarrow \mathrm{n}} \boldsymbol{\sigma}(\boldsymbol{v})=0
$$

where $p$ is the pressure. We will apply this system to the Newtonian fluid, i.e.

$$
\boldsymbol{\sigma}=\eta\left(\nabla \boldsymbol{v}+(\nabla \boldsymbol{v})^{T}-\frac{2}{3} \nabla \cdot \boldsymbol{v} \boldsymbol{I}\right) \equiv 2 \eta\left(\boldsymbol{e}-\frac{1}{3} \nabla \cdot \boldsymbol{v} \boldsymbol{I}\right)
$$

where $\eta$ is the dynamic viscosity and $\boldsymbol{e}$ the strain-rate tensor.

Heat equation

$$
\rho T\left(\frac{\partial s}{\partial t}+\boldsymbol{v} \cdot \nabla s\right)=\nabla \cdot(k \nabla T)+\sigma: \nabla v+Q,
$$


where $T$ is the absolute temperature, $s$ is the entropy per unit mass, $k$ is the thermal conductivity and $Q$ are the volumetric heat sources; the symbol : denotes the total scalar product of the second-order tensors. The first term on the right-hand side of eqn. (6) describes conduction of heat and the second term dissipation of heat, respectively.

If we assume that there is a reference hydrostatic state characterized by $v=0$, when the hydrostatic pressure $p_{0}$, hydrostatic density $\rho_{0}$ and hydrostatic gravity acceleration $g_{0}$ are related by the equation

$$
\nabla p_{0}=\rho_{0} \boldsymbol{g}_{0},
$$

and, moreover, that pressure deviations $\Pi=p-p_{0}$ are negligible in the heat equation, the transfer of heat in a homogeneous material (i.e. entropy may be considered as a function of only $p$ and $T$ ) is then described by the well-known equation

$$
\rho c_{p} \frac{\partial T}{\partial t}=\nabla \cdot(k \nabla T)-\rho c_{p} v \cdot \nabla T-\rho v_{r} \alpha T g+\sigma: \nabla v+Q,
$$

where $c_{p}$ is the isobaric specific heat, $\alpha$ is the thermal expansion coefficient and $v_{r}$ denotes the radial component of velocity. The left-hand side of eqn. (8) represents local changes of heat balance, the second (third) term on the right-hand side describes advection of heat (adiabatic heating/cooling).

Equation of state

$$
\rho=\rho(p, T) .
$$

Today with the advances made in computational quantum mechanics (Tsuchiya et al., 2005) $\rho(p, T)$ can be constructed readily as a look-up table and be part of the physical setup for modelling (Jacobs et al., 2006).

The widely-used Boussinesq approximation linearizes these basic laws near the reference hydrostatic state (e.g. Spiegel and Veronis, 1960; Ogura and Phillips, 1962; Schubert et al., 2001). If we neglect density changes caused by the pressure deviations $\Pi=p-p_{0}$, we may linearize the state equation with respect to the temperature deviations $T-T_{0}$, where $T_{0}$ is a reference temperature, and write

$$
\rho=\rho_{0}\left(1-\alpha\left(T-T_{0}\right)\right) .
$$

This approximation thus means that the influence of hydrostatic pressure (as well as temperature $T_{0}$ ) on density is hidden in a spatial dependence of the reference density $\rho_{0}$. For example, 
Monnereau and Yuen (2002) used in the role of depth-variable density model $\rho_{0}$ the PREM model (Dziewonski and Anderson, 1981).

The reference density $\rho_{0}$ is assumed to be a time-independent function. Considering only the largest term in the equation of continuity, i.e. neglecting thermal expansion, we arrive at the simplified equation

$$
\nabla \cdot\left(\rho_{0} v\right)=0,
$$

see also (Jarvis and McKenzie, 1980). After putting eqns. (7) and (10) into the momentum equation (2) we get

$$
-\nabla \Pi+\nabla \cdot \sigma-\rho_{0} \alpha\left(T-T_{0}\right) g_{0}+\rho_{0}\left(\boldsymbol{g}-g_{0}\right)=\rho_{0}\left(\frac{\partial v}{\partial t}+\boldsymbol{v} \cdot \nabla \boldsymbol{v}\right)
$$

where we neglected the quadratic term $-\rho_{0} \alpha\left(T-T_{0}\right)\left(\boldsymbol{g}-\boldsymbol{g}_{0}\right)$ on the left-hand side and the thermal expansion on the right-hand side, i.e., the changes of the inertial force due to the thermal expansion. Note that the deviation of the gravity acceleration $\boldsymbol{g}-\boldsymbol{g}_{0}$ is due to the self-gravitation of the Earth. The magnitude of the term $\rho_{0}\left(\boldsymbol{g}-\boldsymbol{g}_{0}\right)$ in the mantle is much lower than that of the buoyancy term $-\rho_{0} \alpha\left(T-T_{0}\right) \boldsymbol{g}_{0}$ except largest wavelengths (Ricard et al., 1984), therefore, it does not influence substantially the basic physics of mantle thermal convection. This is the reason why we will omit the self-gravitation term throughout the rest of this study.

Simplification of the heat equation consists in replacing $\rho$ by $\rho_{0}$, i.e.

$$
\rho_{0} c_{p} \frac{\partial T}{\partial t}=\nabla \cdot(k \nabla T)-\rho_{0} c_{p} v \cdot \nabla T-\rho_{0} v_{r} \alpha T g_{0}+\sigma: \nabla v+Q .
$$

The system (11)-(13) is referred to as the anelastic liquid approximation of the basic laws of conservation. However, it is common to neglect compressibility in the equation of continuity (11) and to replace it simply by

$$
\nabla \cdot v=0
$$

The obtained system of equations (12)-(14) is then usually called the extended Boussinesq approximation, e.g. (Christensen and Yuen, 1985), which is suitable for general mantle convection studies because shear heating and adiabatic heating/cooling are the substantial physical mechanisms influencing temperature and velocity patterns. On the other hand, a role played by compressibility in eqn. (11) is minor except for regions of phase transitions. 
The classical Boussinesq approximation, although an oversimplification for mantle convection studies, is suitable for many fluids in laboratory conditions and represents a further substantial simplification of the studied system of equations:

The reference density $\rho_{0}$, the reference gravity acceleration $\boldsymbol{g}_{0}$, the thermal expansion coefficient $\alpha$, the isobaric specific heat $c_{p}$, the thermal conductivity $k$ are constant and the above mentioned system is applied again to the Newtonian fluid with a constant dynamic viscosity $\eta$. Moreover, both dissipation $\sigma: \nabla \boldsymbol{v}$ and adiabatic heating/cooling $-\rho_{0} v_{r} \alpha T g_{0}$ are not taken into account. We thus get the system

$$
\begin{gathered}
\nabla \cdot \boldsymbol{v}=0 \\
-\nabla \Pi+\eta \nabla^{2} \boldsymbol{v}-\rho_{0} \alpha\left(T-T_{0}\right) \boldsymbol{g}_{0}=\rho_{0}\left(\frac{\partial \boldsymbol{v}}{\partial t}+\boldsymbol{v} \cdot \nabla \boldsymbol{v}\right) \\
\frac{\partial T}{\partial t}=\kappa \nabla^{2} T-\boldsymbol{v} \cdot \nabla T+\frac{Q}{\rho_{0} c_{p}}
\end{gathered}
$$

where $\kappa=k / \rho_{0} c_{p}$ is the thermal diffusivity. One popularity gained by the extended Boussinesq approximation is that it is easy to convert a Boussinesq code to extended-Boussinesq code, and computationally this is much faster than the anelastic approximation (Jarvis and Mc Kenzie, 1980).

Introduce now new dimensionless variables (denoted by the star *) by means of the relations

$r=d r^{*}, \quad t=\frac{d^{2}}{\kappa_{s}} t^{*}, \quad v=\frac{\kappa_{s}}{d} v^{*}, \quad \Pi=\frac{\eta_{s} \kappa_{s}}{d^{2}} \Pi^{*}, \quad T=T_{s}+\left(T_{b}-T_{s}\right) T^{*}$,

where $\boldsymbol{r}$ is the position vector and $d$ is the characteristic dimension of the system-e.g., the thickness of the mantle in mantle convection problems or the vertical dimension of the fluid layer in the problems in Cartesian geometry - and the subscript ${ }_{s}$ denotes surface values of corresponding quantities, whereas $b$ denotes their bottom values. The system (12)-(14) in dimensionless variables thus reads

$$
\begin{gathered}
\nabla^{*} \cdot v^{*}=0, \\
-\nabla^{*} \Pi^{*}+\nabla^{*} \cdot\left(\frac{\eta}{\eta_{s}}\left(\nabla^{*} v^{*}+\left(\nabla^{*} v^{*}\right)^{T}\right)\right)+R a_{s} \frac{\alpha}{\alpha_{s}}\left(T^{*}-T_{0}^{*}\right) e_{r}=P r_{s}{ }^{-1}\left(\frac{\partial v^{*}}{\partial t^{*}}+v^{*} \cdot \nabla^{*} v^{*}\right),
\end{gathered}
$$

with $\boldsymbol{e}_{r}$ being the radial unit vector, 


$$
\begin{gathered}
\frac{\partial T^{*}}{\partial t^{*}}=\nabla^{*} \cdot\left(\frac{k}{k_{s}} \nabla^{*} T^{*}\right)-v^{*} \cdot \nabla^{*} T^{*}+\frac{R a q_{s}}{R a_{s}}- \\
-D i_{s} \frac{\alpha}{\alpha_{s}}\left(T^{*}+\frac{T_{s}}{T_{b}-T_{s}}\right) v_{r}^{*}+\frac{D i_{s}}{R a_{s}} \frac{\eta}{\eta_{s}}\left(\nabla^{*} v^{*}+\left(\nabla^{*} v^{*}\right)^{T}\right): \nabla^{*} v^{*},
\end{gathered}
$$

where we introduced the (surface) Prandtl number $P r_{s}=\eta_{s} / \rho_{0} \kappa_{s}$, the (surface) Rayleigh number $R a_{s}=\rho_{0} \alpha_{s}\left(T_{b}-T_{s}\right) g_{0} d^{3} / \eta_{s} \kappa_{s}$, the (surface) Rayleigh number for heat sources

$R a q_{s}=\rho_{0} \alpha_{s} g_{0} Q d^{5} / \eta_{s} \kappa_{s} k_{s}$ and the (surface) dissipation number $D i_{s}=\alpha_{s} g_{0} d / c_{p}$. Note that the dimensionless heating term $R=R a q_{s} / R a_{s}=k_{s}\left(T_{b}-T_{s}\right) / Q d^{2}$.

As the Prandtl number is extremely high (more than $10^{20}$, something like $10^{22}$ at least) for mantle convection applications, we may use the infinite Prandtl number approximation, i.e. we may replace eqn. (20) by

$$
-\nabla^{*} \Pi^{*}+\nabla^{*} \cdot\left(\frac{\eta}{\eta_{s}}\left(\nabla^{*} v^{*}+\left(\nabla^{*} v^{*}\right)^{T}\right)\right)+R a_{s} \frac{\alpha}{\alpha_{s}}\left(T^{*}-T_{0}^{*}\right) e_{r}=0 .
$$

From the physical point of view this approximation means that the inertial force is negligible. As to the other numbers: In most of the models of this study we have used $R a_{s}=10^{7}, D i_{s}=0.5$ and $\mathrm{R}=3$, which are standard values for mantle material properties (e.g. Turcotte and Schubert, 2002). Enhanced Joule heating (Braginskii and Meitlis, 1987) due to an increase of electrical conductivity at the base of the mantle from electronic transitions (Badro et al., 2004; Li et al., 2005) in the D"-layer can also influence the thermal-electrical coupling between the core and the lower-mantle. We will, however, neglect Joule heating in this study as it should play a remarkable role only if it reaches very high magnitudes (Matyska and Moser, 1994).

\section{Cartesian geometry}

In this section we will describe the equations, which were used to obtain numerical models presented in this study. They are written in the Cartesian coordinates $(x, z)$, where $x$ is a dimensionless horizontal coordinate and $z$ denotes the dimensionless depth, i.e. $z=0$ at the surface and $z=1$ at the bottom of a convecting layer. We can now obtain velocity field satisfying the equation of continuity (19) by expressing velocity in the form

$$
v^{*} \equiv\left(v_{x}^{*}, v_{z}^{*}\right)=\left(\frac{\partial \psi}{\partial z},-\frac{\partial \psi}{\partial x}\right)
$$

where $\psi=\psi(x, z)$ is the stream function. As 


$$
v^{*} \cdot \nabla^{*} \psi=0
$$

it is clear that the isolines of $\psi$ are the streamlines of velocity.

The momentum equation (22) can now be rewritten to

$$
\begin{aligned}
& -\frac{\partial \Pi^{*}}{\partial x}+\frac{\partial}{\partial x}\left[2 \frac{\eta}{\eta_{s}} \frac{\partial^{2} \psi}{\partial x \partial z}\right]+\frac{\partial}{\partial z}\left[\frac{\eta}{\eta_{s}}\left(\frac{\partial^{2} \psi}{\partial z^{2}}-\frac{\partial^{2} \psi}{\partial x^{2}}\right)\right]=0 \\
& -\frac{\partial \Pi^{*}}{\partial z}-\frac{\partial}{\partial z}\left[2 \frac{\eta}{\eta_{s}} \frac{\partial^{2} \psi}{\partial x \partial z}\right]+\frac{\partial}{\partial x}\left[\frac{\eta}{\eta_{s}}\left(\frac{\partial^{2} \psi}{\partial z^{2}}-\frac{\partial^{2} \psi}{\partial x^{2}}\right)\right]=R a_{s} \frac{\alpha}{\alpha_{s}}\left(T^{*}-T_{0}^{*}\right) .
\end{aligned}
$$

After applying the operator $\partial / \partial z$ to (25), the operator $\partial / \partial x$ to (26), and subtracting both equations, we obtain the final form of the momentum equation

$$
\left(\frac{\partial^{2}}{\partial z^{2}}-\frac{\partial^{2}}{\partial x^{2}}\right)\left[\frac{\eta}{\eta_{s}}\left(\frac{\partial^{2} \psi}{\partial z^{2}}-\frac{\partial^{2} \psi}{\partial x^{2}}\right)\right]+4 \frac{\partial^{2}}{\partial x \partial z}\left[\frac{\eta}{\eta_{s}} \frac{\partial^{2} \psi}{\partial x \partial z}\right]=-R a_{s} \frac{\partial}{\partial x}\left[\frac{\alpha}{\alpha_{s}}\left(T^{*}-T_{0}^{*}\right)\right]
$$

The heat equation (21) now reads

$$
\begin{gathered}
\frac{\partial T^{*}}{\partial t^{*}}=\frac{\partial}{\partial x}\left(\frac{k}{k_{s}} \frac{\partial T^{*}}{\partial x}\right)+\frac{\partial}{\partial z}\left(\frac{k}{k_{s}} \frac{\partial T^{*}}{\partial z}\right)-\frac{\partial \psi}{\partial z} \frac{\partial T^{*}}{\partial x}+\frac{\partial \psi}{\partial x} \frac{\partial T^{*}}{\partial z}+R- \\
-D i_{s} \frac{\alpha}{\alpha_{s}}\left(T^{*}+\frac{T_{s}}{T_{b}-T_{s}}\right) \frac{\partial \psi}{\partial x}+\frac{D i_{s}}{R a_{s}} \frac{\eta}{\eta_{s}}\left[\left(\frac{\partial^{2} \psi}{\partial z^{2}}-\frac{\partial^{2} \psi}{\partial x^{2}}\right)^{2}+4\left(\frac{\partial^{2} \psi}{\partial x \partial z}\right)^{2}\right]= \\
=\frac{k}{k_{s}} \nabla^{* 2} T^{*}+\frac{1}{k_{s}} \frac{\partial k}{\partial z} \frac{\partial T^{*}}{\partial z}+\frac{1}{k_{s}} \frac{\partial k}{\partial T^{*}}\left(\nabla^{*} T^{*} \cdot \nabla^{*} T^{*}\right)-\frac{\partial \psi}{\partial z} \frac{\partial T^{*}}{\partial x}+\frac{\partial \psi}{\partial x} \frac{\partial T^{*}}{\partial z}+R- \\
-D i_{s} \frac{\alpha}{\alpha_{s}}\left(T^{*}+\frac{T_{s}}{T_{b}-T_{s}}\right) \frac{\partial \psi}{\partial x}+\frac{D i_{s}}{R a_{s}} \frac{\eta}{\eta_{s}}\left[\left(\frac{\partial^{2} \psi}{\partial z^{2}}-\frac{\partial^{2} \psi}{\partial x^{2}}\right)^{2}+4\left(\frac{\partial^{2} \psi}{\partial x \partial z}\right)^{2}\right],
\end{gathered}
$$

as we will consider $k=k\left(z, T^{*}\right)$ (see eqn. (42) below). We can see that this heat equation is strongly non-linear as it contains the non-linear terms describing the following effects: non-linear diffusion of heat caused by the temperature dependence of thermal conductivity, horizontal and vertical advection of heat, adiabatic heating/cooling, dissipation of heat. Additional non-linearity, which will appear in the equation (27), will be the temperature-dependence of viscosity (see eqns. (40), (41)). In principle, non-linear creep mechanisms, such as dislocation creep characterized by a dependence of viscosity on the strain-rate tensor, can also be taken into account but dislocation creep dominate near cold slabs and not in hot lower-mantle regions (McNamara et al., 2001); nevertheless it can still be important in olivine in the upper-mantle.

The two scalar equations (27), (28) for the two scalar unknowns $\psi$ and $T^{*}$ thus describe thermal convection in a 2-D Cartesian box $<0, a>\mathrm{x}<0,1>$, where $a$ is the aspect ratio of the box. 
To complete the equations, we need to add boundary conditions. We will consider all boundaries to be impermeable with a free-slip, i.e.

$$
\psi=\frac{\partial^{2} \psi}{\partial x^{2}}=0 \quad \text { for } \quad x=0, a \quad \text { and } \quad \psi=\frac{\partial^{2} \psi}{\partial z^{2}}=0 \quad \text { for } \quad z=0,1
$$

We will assume no horizontal heat flow at the sidewalls, thus

$$
\frac{\partial T^{*}}{\partial x}=0 \quad \text { for } x=0, a \quad \text { and } \quad T^{*}=0 \text { for } z=0, T^{*}=1 \text { for } z=1
$$

In other words, the boundary conditions at the sidewalls are reflecting.

The non-linearities of the dynamical system (27)-(30) are the reason why both the timeevolution of the system and its spatial properties are crucially dependent on values of the physical properties. For example, it is well-known that the Rayleigh number is the key parameter controlling the chaoticity of this system (e.g. Turcotte, 1992; Schubert et al., 2001). In this study we will also demonstrate that depth- and temperature-dependence of physical properties such as viscosity, thermal expansivity and/or conductivity are important factors for the length-scales of convecting fluid and its time-behavior as well.

\section{Phase changes}

Phase changes in multi-component systems such as mantle minerals are characterized by existence of zones, where two or more phases coincide together. For simplicity, we will assume that the depth span of these zones is negligible and that we may describe them as the phase interfaces with jumps of density and entropy. Lateral variations of temperature generate undulations of phase interface topography, which represent substantial additional buoyancy force due to the density jump $\Delta \rho$. Moreover, the jump in the entropy results in release or consumption of latent heat when material flows through the phase change interfaces. We neglect the density jumps in the continuity equation, as it can only change the velocity by a few percent.

If $\Gamma$ is the Clapeyron slope of such an interface, its undulation $h$ (measured downward) caused by the temperature difference $T-T_{0}$ is approximately

$$
h=\Gamma\left(T-T_{0}\right) / \rho_{0} g_{0} .
$$

The buoyancy of the undulation can thus be described by means of the additional pressure $-\Delta \rho g_{0} h$, which has a character of an external force in the momentum equation. In the first-order approximation we may thus add the force term

$$
f=\frac{\Delta \rho}{\rho_{0}} \Gamma\left(T-T_{0}\right) \delta\left(r-r_{p}\right) e_{r}
$$


into the left-hand side of (12) or the force term

$$
f^{*}=\frac{\Delta \rho}{\alpha_{s} \rho_{0}^{2} g d} \Gamma R a_{s}\left(T^{*}-T_{0}^{*}\right) \delta\left(r^{*}-r_{p}^{*}\right) e_{r}
$$

into the left-hand side of (20). Here $\delta$ is the Dirac $\delta$-function and $r_{p}$ is the radial distance of the phase interface under the temperature $T_{0}$.

From a formal point of view, we only replace the thermal expansivity $\alpha$ by

$$
\alpha^{\prime}=\alpha+\frac{\Delta \rho}{\rho_{0}^{2} g_{0}} \Gamma \delta\left(r-r_{p}\right)
$$

or $\alpha / \alpha_{s}$ by

$$
\frac{\alpha^{\prime}}{\alpha_{s}}=\frac{\alpha}{\alpha_{s}}+\frac{\Delta \rho}{\alpha_{s} \rho_{0}^{2} g_{0} d} \Gamma \delta\left(r^{*}-r_{p}^{*}\right) \equiv \frac{\alpha}{\alpha_{s}}+P \delta\left(r^{*}-r_{p}^{*}\right),
$$

where $P=\Delta \rho \Gamma / \alpha_{s} \rho_{0}^{2} g_{0} d$ is called the phase buoyancy parameter, see also (Christensen and Yuen, 1985). It is clear that the same replacement of the thermal expansivity in the adiabatic heating/cooling term of the heat equation then includes the latent heat release or consumption.

\section{Thermal expansivity, viscosity and radiative heat transfer}

We have used the two profiles of the depth-dependent thermal expansivity. The first model has been parameterized to

$$
\frac{\alpha}{\alpha_{s}}=\frac{8}{(2+z)^{3}},
$$

where the thermal expansivity decreases by $8 / 27$ across the whole mantle, see e.g. (Zhao and Yuen, 1987). Quite recently, Katsura et al. (2005) announced that Anderson-Grüneisen parameter of perovskite is close to 10 , and thus the thermal expansivity decrease over the lowermantle should be higher. By approximating a linear depth-dependence of density in both the upper- and the lower-mantle, and assuming that Anderson-Grüneisen parameter of the uppermantle minerals is close to 5, which corresponds to the estimates for olivine (Chopelas and Boehler, 1992), we arrived at the following relations (see Fig. 1), 


$$
\begin{gathered}
\frac{\alpha}{\alpha_{s}}=(1+0.78 z)^{-5} \text { if } 0 \leq z \leq 0.23 \\
\frac{\alpha}{\alpha_{s}}=0.44(1+0.35(z-0.23))^{-10} \text { if } 0.23<z \leq 1 .
\end{gathered}
$$

Note that the magnitude of thermal expansivity at the top of the lower-mantle should be about $3.5 \times 10^{-5} \mathrm{~K}^{-1}$ according to Katsura et al. (2005).

We have considered the depth-dependence of viscosity in the form used by Hanyk et al. (1995), see also Fig. 1,

$$
\frac{\eta_{0}(z)}{\eta_{s}}=1+214.3 z \exp \left(-16.7(0.7-z)^{2}\right) \text {, }
$$

which gives rise to the lower-mantle viscosity maximum at around $1800 \mathrm{~km}$. Such a maximum is consistent with dynamic geoid and postglacial rebound modelling (Ricard and Wuming, 1991; Forte and Mitrovica, 2001; Mitrovica and Forte, 2004).

In order to take into account also a temperature-dependence of viscosity, we included the temperature-dependent part

$$
f\left(T^{*}\right)=\exp \left(10.0\left(\frac{0.6}{0.2+T^{*}}-1\right)\right)
$$

in the Arrhenius form of a thermally activated process (e.g. Davies, 1999; see also Matyska and Yuen, 2006). The composite temperature- and depth-dependent viscosity, which has been considered in complex models, is given by

$$
\frac{\eta\left(z, T^{*}\right)}{\eta_{s}}=\frac{\eta_{0}(z)}{\eta_{s}} \min \left\{100, \max \left\{0.01, f\left(T^{*}\right)\right\}\right\},
$$

i.e. the temperature-dependence of dimensionless viscosity is confined by the limits 0.01 and 100 so that the momentum equation may be solved by a conjugate gradient iterative solver.

As one of the main aims of this study is to demonstrate potential creation of the lowermantle superplumes by means of the radiative transfer of heat, we have neglected depth- and temperature-dependence of phonon thermal conductivity (Hofmeister, 1999) and considered the total thermal conductivity in the form 


$$
\frac{k\left(z, T^{*}\right)}{k_{s}}=1+g(z)\left(\frac{T_{s}}{T_{b}-T_{s}}+T^{*}\right)^{3},
$$

where the prefactor $g(z)$ enables to include depth-dependence of radiative transfer of heat due to the changes of composition, opacity, etc.

The set of equations (27)-(30), which describes our numerical models, thus consists of the fourth-order linear elliptic equation (27) for the streamfunction $\psi$ with the boundary conditions (29) (with both laterally and vertically varying coefficients because of the presence of $\left.\eta\left(z, T^{*}\right) / \eta_{s}\right)$ and the non-linear time-evolutionary advection-diffusion equation (28) for the temperature $T^{*}$ with the boundary conditions (30). The depth-changes of thermal expansivity result in the changes of the buoyancy forcing term in the elliptic equation as well as in the changes of adiabatic heating/cooling in the time-evolutionary equation. The inclusion of radiative transfer of heat by means of the temperature-dependent thermal conductivity then changes the ratio between diffusion and advection of heat.

Computations have been carried out in a wide box with an aspect-ratio of 10 to avoid the influence of side-boundaries. We have used 1281 x 129 equally distributed nodal points for a second-order finite difference scheme in space. The elliptic equation has been solved by the conjugate gradient iterative scheme and a second-order Runge-Kutta scheme has been applied for the time-stepping in the time-evolutionary equation.

\section{RESULTS}

\section{Basic physics of simple models-influence of the depth-dependence of mantle properties}

We begin in Fig. 2 by illustrating the style of mantle convection without the presence of major phase transitions but with the extended Boussinesq approximation. We will vary a whole gamut of depth-dependent properties in thermal expansion coefficient and viscosity. The top panel is a typical snapshot of temperature field in the long-time regime for constant material properties and $R a_{s}=10^{6}$. The dissipation number is 0.5 . Convection is rather chaotic with many cold downwellings and hot upwellings. We can see that the role played by adiabatic heating/cooling is substantial in such a model; plume heads disappear before reaching the top boundary-layer of convection because of the rapid cooling due to constant thermal expansivity (Zhao and Yuen, 1987). This extended Boussinesq model thus does not correspond to the classical Boussinesq idea of plumes generating locally hot material, which then rises and interacts with the cold upper boundary-layer (lithosphere). This main feature of convection is not substantially changed when the Rayleigh number is increased to $10^{7}$ in the second panel. The only remarkable difference from the previous case is that influence of the internal heating is minor and thus we get more symmetry between the cold and hot anomalies.

The middle panel shows the case when the depth-dependent viscosity (see eqn. 39) is taken into account. Since an increase of viscosity corresponds to a relative decrease of buoyancy in the momentum equation, convection is then characterized by a fewer big stable plumes, emerging from the lower thermal boundary-layer, see also (Hansen et al., 1993) for 2-D models and (Cserepes, 1993) for 3-D modelling. It is of great geophysical interest that there is a high lateral temperature contrast between the plume and a very cold ambient mantle in the lower part of the convecting layer but this contrast becomes small at the top of the model. Such a large 
thermal contrast in the lower-mantle may induce seismic velocity contrasts, of a couple of per cent (e.g. Ni and Helmberger, 2003). The cold thermal boundary-layer at the top of the model is unstable and acts as a source of cold "lumps" which slowly fall to the "viscosity hill" (e.g. Ricard and Wuming, 1991; Mitrovica and Forte, 2004) in the mid lower-mantle.

The bottom two panels represent cases with decreasing thermal expansivity in the lowermantle. They reveal that a similar stabilization of convection cells, creation of big plumes and lowering the average temperature can be produced also by a decrease of thermal expansivity in the lower-mantle as it causes a decrease of buoyancy. There is, however, one substantial difference: low thermal expansivity at the bottom of the model means also a low adiabatic cooling of the bottom part of (super)plumes. It results in higher plume temperatures and thus very hot plume heads (see also Zhao and Yuen, 1987) are able to reach and interact with the cold upper boundary-layer.

In order to deal with more realistic models, where the critical dependence of mantle heat transfer on combinations of mantle properties will be demonstrated, we will incorporate the effects of variable viscosity, radiative thermal conductivity and the two major phase transitions in the upper- and lower-mantle, which are illustrated in Fig. 3. These more realistic models will allow for a greater variety of dynamical possibilities.

\section{Complex models}

First, we show the results for the old thermal expansivity profile, decreasing by $8 / 27$ across the mantle (see eqn. 36), depth- and temperature-dependent viscosity and the two phase transitions characterized by the buoyancy parameters $P_{670}=-0.15, \mathrm{P}_{\mathrm{D}^{\prime \prime}}=0.10$. Typical snapshots of temperature are shown in Fig. 4, thermal anomalies obtained by subtracting out the horizontally averaged temperature are shown in Fig. 5, and corresponding stream functions are shown in Fig. 6. The results in the top panel were obtained for the constant thermal conductivity $k=1$ considered for the entire mantle. We can see that convection is partially layered and the consequence of the temperature-dependence of viscosity is the formation of large cold anomalies that are able to penetrate the phase boundary at the $670 \mathrm{~km}$ depth. The highest velocity of downwellings is reached in the lower-mantle. This downward flow is balanced at $670 \mathrm{~km}$ by small plumes originated below this interface, from which hot material is ejected into the uppermantle. The counterpart of the downwellings in the lower-mantle are the plumes, which are bigger than those in the upper-mantle and are mainly visible in the bottom half of the lowermantle.

The next three panels show the influence of increasing radiative transfer of heat through the D"-layer, which is parameterized by the coefficient $g$ adjacent to the cube of absolute temperature in the radiative thermal conductivity, see eqn. (42). An important consequence of this phenomenon is an increase of averaged temperature in the lower-mantle and, subsequently, a much lower temperature contrast between the lower-mantle (super)plumes and the ambient mantle. The vigor of convection is increased together with an enhancement of partial layering.

An outstanding result of these models is the creation of a very hot, thin layer just below the $670 \mathrm{~km}$, which is again the source of small upper-mantle plumes. Jetting of hot material into the upper-mantle is periodically repeated ("inverse flushing events") in several places thus resulting in the appearance of many upper-mantle plumes, which are then drifted horizontally by an upper-mantle mean flow towards the central location of the main upper-mantle plume. Positions of the central upper-mantle plumes are, however, controlled by the lower-mantle superplumes. Stability of the lower-mantle superplumes and the attraction of the upper-mantle 
plumes into one place and subsequent plume-plume interactions may then explain why the upper-mantle plumes are able to act as a "fixed" sublithospheric heat source for a long time. Fig. 7 illustrates that this hot layer below the $670 \mathrm{~km}$ together with the upper-mantle plumes form the regions of the lowest viscosities in our models, which corresponds to the "second asthenosphere, as revealed by Kido and Čadek (1997) under oceanic regions; see also (Mitrovica and Forte, 2004).

We computed also the model, where the radiative heating term is taken into account in the whole mantle. Such an overall increase of thermal conductivity further boosted the convective velocities, where cold downwellings in the lower-mantle are in the form of huge blobs and the average temperature of the lower-mantle decreased. On the other hand, lateral temperature contrast between the upper-mantle plumes and the ambient upper-mantle became smaller.

Fig. 8 illustrates that the shear heating generated inside the convecting layers is maximal in downwellings because of the combination of high viscosities together with high rates of deformation; the secondary maxima are usually reached inside the upper-mantle plumes regions, thus generating the hot layer under the transition zone, as mentioned above. Thus we can see clearly in Fig. 8 that shear heating can be locally much higher than the averaged bulk heating and so it should not be neglected in physical descriptions of complex models where there exist many regions with stagnation points, where flows undergo severe deformation.

Recent measurements on perovskite (Katsura, 2005) indicate that decrease of thermal expansivity with increasing pressure is much higher than previously estimated for olivine (Chopelas and Boehler, 1992). For this new thermal expansivity profile in the lower-mantlewith a decrease of thermal expansivity in the lower-mantle by a factor of 11 -we have considered various models with different types of mantle thermal conductivities, ranging from constant thermal conductivity to prevailing radiative thermal conductivity. Similarly as for the old thermal expansivity profile, we have also studied a suite of intermediate cases, where the radiative conductivity is present only in the D"-layer and is varied from twice to 10 times the constant thermal conductivity value. Figures 9 and 10 show the temperature fields and the residual temperature fields. Since the decrease of thermal coefficient of expansion results in a decrease in the averaged temperature, the lower-mantle plumes can be discerned much easier than in the previous cases in Figs. 7 and 8. It is clear that the role of radiative thermal conductivity and depth-dependent thermal expansivity can be quite profound on the development of the lower-mantle upwellings, since the reference model with constant thermal conductivity resulted in clusters of smaller unstable lower-mantle plumes. In contrast, a substantial increase of thermal conductivity in D"-layer gives rise to the production of lowermantle superplumes. Broad upwellings are much more emphasized with a thin radiative thermal conductive layer in the D"-layer than with the radiative thermal conductivity distributed throughout the mantle.

In these models we obtained also flow reversals (see the streamlines shown in Fig. 11) at $670 \mathrm{~km}$ boundary and partial layered convection. Flow reversals can generate a considerable amount of mechanical heating. There is a low viscosity region in the vicinity of the transition zone (see Fig. 12), due to the injection of hot lower-mantle material. Shear heating (Fig. 13) is higher than in the previous models with a smaller decrease in the thermal expansivity. There are even places located below the $670 \mathrm{~km}$ boundary, which are overheated by viscous heating to very high temperatures, exceeding the dimensionless temperature of unity, which is the temperature at the core-mantle boundary (we have used a periodic color scale and thus these sites 
are portrayed by dark blue inside dark red regions). The upper-mantle plumes are again small but very hot.

Note that the convection pattern at $670 \mathrm{~km}$ depth is sensitive to the magnitude of the phase buoyancy parameter $P_{670}$, buoyancy of the lower-mantle superplumes and viscosity stratification, because a low viscosity zone below the interface between the mantles facilitates horizontal flow. We used lower "new" thermal expansivity (see eqns. (37), (38)) in the second set of models and obtained partial layering for $P_{670}=-0.08$, which is in good agreement with the values estimated for the spinel to perovskite phase change. On the other hand, in the first set of models with the "old" thermal expansivity profile (see eqn. (36)) buoyancy of the lower-mantle superplumes is higher and we demonstrated that similar partial layering of convection can be obtained for $P_{670}=-0.15$, i.e. with slightly overestimated magnitude of the buoyancy parameter.

The change of the model behavior in the case, when the radiative thermal conductivity is considered in the whole mantle, see the bottom panels of Figs. 9-13, is now much remarkable. The combined effect of the small value of thermal expansivity (i.e. small adiabatic gradient) with higher velocities of convection results in a well developed lower thermal boundary-layer. Subsequently, averaged lower-mantle temperature is lower, temperature contrast between the superplume and the ambient mantle is higher and the superplumes are thinner. Moreover, the amount of material passing through the $670 \mathrm{~km}$ interface is higher because of higher buoyancy. This finally results in thicker upper-mantle plumes. The consequence is that the surface Nusselt number, i.e. the surface heat flow, is rather high as it oscillates between 20 and 45 . On the other hand, typical surface Nusselt numbers of the models with high thermal conductivity confined to D"-layer are lower and usually oscillate between 10 and 15. It is interesting that the model with radiative transfer of heat in the whole mantle yields similar bi-modal plumes to those obtained by van Keken et al. (1992) for an ad hoc stratification of rheology and constant thermal conductivity.

In order to understand better the small-scale features of upper-mantle plumes, we zoomed into the plumes in the upper-mantle in Figs. 14 and 15 for both thermal expansivity models. It is obvious that many upper-mantle plumes come from the transition zone. The overall morphology of the upper-mantle upwellings is similar in both models, with the upper-mantle being slightly hotter for the more steeply decreasing thermal expansivity. Only in the case with the radiative thermal conductivity prevailing throughout the mantle do we have a situation where the uppermantle plume is directly fed from the deep lower-mantle (see bottom of Fig. 15). There is also evidence of overheating (see the dark blue color) in some local areas corresponding to the roots of upper-mantle plumes. Although such overheating need not be fully realistic in the Earth, it points to the importance of shear heating in convection dynamics.

In order to demonstrate the time-scale of upper-mantle plume dynamics, we present several snapshots of temperature showing the temporal evolution of the upper-mantle plumes in the case, when the thermal conductivity in the D"-layer is dominated by the radiative term, whereas radiative heat transfer is negligible above the D"-layer (see Fig. 16). Time steps between two subsequent panels correspond to about $15 \mathrm{Myr}$ in dimensional time. We note that nonNewtonian rheology can result in shorter timescales of about a few million years in the uppermantle (Larsen and Yuen, 1997). In our model temperature of the plume roots below the $670 \mathrm{~km}$ interface is very high - it can even be locally slightly higher than the temperature of the CMB, which results in faster plume-plume interactions and more turbulent plume evolution in comparison to places, where the upper-mantle plume-roots are colder below the transition zone. 


\section{CONCLUSIONS}

In the past decade, seismic imaging of the mantle has improved immensely, due to the great advances in data-acquisition (Grand et al., 1997; Ritsema et al., 1999), theoretical developments in finite-frequency effects (Montelli et al., 2004; Zhou et al., 2005) and computational hardware and numerical techniques (Komatisch and Tromp, 2002a,b). Both superplumes in the lower-mantle and smaller upper-mantle plumes have now been unveiled by body waves (Zhao, 2001, 2004; Lei and Zhao, 2005; Pilidou et al., 2005) and surface waves (Zhou et al., 2004). These images have provoked undoubtedly a revision in the traditional concept of what mantle upwellings should appear because we have been so ingrained by ideas inculcated in the 1980's from steady-state laboratory experiments, using simple fluids and steady point source of heating (e.g. Whitehead and Luther, 1975; Olson and Singer, 1985). These recent tomographic images have revealed clearly the multi-scale nature of mantle plumes, which we have portrayed artistically in Fig. 17. Implicit in this drawing is the multiscale nature in both time and space, because mantle flow is intrinsically very time-dependent because of the nonlinear physics present in the transport properties and the phase transitions and the feedback loops between the various processes. In Fig. 17 we see the different origins of the different spatial scales of mantle plumes. Such a change of spatial scales between the upper- and lowermantle is also consistent with corresponding change of spatial tomographic spectra (Dziewonski, 2000).

In numerical models of mantle convection, the superplumes in the lower-mantle can be created and stabilized in both time and space by the viscosity stratification (e.g. Hansen et al., 1993) and increased thermal conductivity (e.g. Matyska et al., 1994; van den Berg et al., 2001, 2002; Dubuffet et al., 2002; Matyska and Yuen, 2006; Naliboff and Kellogg, 2006), which should be present due to the radiative heat transfer. However, radiative transfer of heat in the deep mantle is still a matter of controversy. It should be important or even dominant in olivine and perovskite (Hofmeister 1999, 2005; Badro, 2004; Gibert et al., 2005) as well as in postperovskite (Mao et al., 2005) but a decrease of radiative heat transfer with increase of pressure was observed for magnesiowüstite (Goncharov et al., 2006). Stabilization of superplumes enables forward studies of their properties, such as the adiabaticity of the superplume mode of heat transfer (Matyska and Yuen, 2001). Here we showed that a decrease of thermal expansivity with depth is another factor facilitating existence and stability of the lower-mantle superplumes. Moreover, increased thermal conductivity at the base of the mantle together with intensive shear heating at the $670 \mathrm{~km}$ depth is able to create the low viscosity zone (Kido and Čadek, 1997; Mitrovica and Forte, 2004) acting as the source of the upper-mantle smaller plumes, which are stabilized by interaction with the lower-mantle superplumes. Note that there can be also chemical heterogeneities associated with the seismically observed superplumes (Ishii and Tromp, 1999; Trampert et al., 2004), which can be modelled in the framework of thermo-chemical convection (e.g. Tan and Gurnis, 2005). Together with iron-rich patches in post-perovskite (Mao et al., 2004, 2006) these chemical heterogeneities could also stabilize lower-mantle convection. It is still a problem how to distinguish between thermal and chemical heterogeneities; for example, the magnitude of density heterogeneities inferred directly from tomographic models is similar to that obtained from thermal convection models (Matyska and Yuen, 2002).

Smaller plumes with a greater propensity for time-dependence because of the lower viscosity and thermal conductivity due to water contents have a shorter lifetime (e.g. Davaille and Vatteville, 2005) and emerge rapidly from the transition zone, which is further aided by 
non-Newtonian rheology in the upper-mantle. In other words, there is not only a multi-scale spatial nature amongst mantle plumes, but also richness in the temporal spectrum, which can span over several orders of magnitude. From the Taylor hypothesis (Zaman and Hussain, 1981; Meneveau and Sreenivasan, 1991) in fluid mechanics, we would expect that in a strongly nonlinear regime larger scale coherent structures would have a longer lifetime than the smallerscale features. In the interpretation of tomographic images one must then keep in mind that the classical picture of a mantle plume with a long conduit connecting to its source at a thermal boundary-layer is only valid for a short duration of time, before detachment process occurs. This criterion is especially true in the upper-mantle, where the lifetime of plumes may be only of the order of 10 million years from boundary-layer stability estimates based on the physical properties of the transition zone (e.g. Howard, 1964). In this connection Maruyama (1994) has offered compelling geological arguments concerning the long lifetime of the superplume under the central Pacific.

Our aim in this paper is to demonstrate that by using realistic physics, such as the depthdependent thermal expansivity, variable viscosity, radiative thermal conductivity and phase transitions, one can also produce a rich spectrum in both the spatial and temporal scales of mantle upwellings for realistic mantle conditions without going into the hard turbulent thermal convection regime (Yuen et al., 1993). Although our modelling was in 2-D, the recent 3-D findings in a Cartesian box with an aspect-ratio of $6 \times 6 \times 1$ by Kameyama and Yuen (2006) show that convection behavior under the presence of the post-perovskite phase transition in 3-D is similar to the results obtained in 2-D. Therefore, we maintain that our results may be representative of convection in the Earth's mantle. Indeed, one is hard-pressed to do the same in laboratory experiments with simple fluids and in a heated from below configuration, even at very high Rayleigh numbers. We hope that this paper would stimulate more realistic numerical modeling of mantle plumes in the future with a resurgent focus on the transient nature of mantle plumes (King and Ritsema, 2000; Davaille and Vattewille, 2005) and their interactions with the lithosphere (Thoraval et al., 2006). With the ever relentless drive toward petascale computing (Cohen, 2005), geodynamicists can overcome the current numerical limitations in speed, memory and data-storage and can address in due course some of the issues raised above for both thermal and thermal-chemical convection, which is a much more difficult computational problem having the potential to broaden complexity of plume modeling (Farnetani and Samuel, 2005).

\section{ACKNOWLEDGEMENTS}

We highly appreciate constructive reviews and comments by Gillian Foulger, Donna Jurdy, Arie van den Berg, Garrett Ito and Scott King. We thank discussions with Cesar da Silva, Renata Wentzcovitch, Charley Kameyama, Shige Maruyama, and Marc Monnereau. We thank Donna Jurdy also for her encouragements in writing this paper and Ying-chun Liu for her drawings. This research has been supported by National Science Foundation CSEDI and ITR grants and by the Czech Science Foundation grant 205/06/0580.

\section{REFERENCES}

Allegre, C.J., and Turcotte, D.L., 1985, Geodynamic mixing in the mesosphere boundary layer 
and the origin of oceanic islands: Geophys. Res. Lett., v. 12, p. 207-210.

Badro, J., Rueff, J.-P., Vankó, G., Monaco, G., Fiquet, G., and Guyot, F., 2004, Electronic transitions in perovskite: Possible non-convecting layers in the lower mantle: Science, v. 305, p. 383-386.

Braginskii, S.I., and Meitlis, V.P., 1987, Overheating instability in the lower mantle near the boundary with the core: Izvestiya, Earth Phys., v. 23, p. 646-649.

Burke, K., and Wilson, J.T., 1976, Hotspots on the Earth's surface: Sci. Am., v. 235, p. 46-57.

Christensen, U.R., and Yuen, D.A., 1985, Layered convection induced by phase transitions: J. Geophys. Res., v. 90, p. 10291-10300.

Chopelas, A., and Boehler, R., 1992, Thermal expansivity in the lower mantle: Geophys. Res. Lett., v. 19, p. 1983-1986.

Cohen, R.E., editor, 2005, High-performance computing requirements for the computational solid Earth sciences: 96 p. http://www.geo-prose.com/computational_SES.html.

Courtillot, V., Davaille, A., Besse, J., and Stock, J., 2003, Three distinct types of hotspots in the Earth's mantle: Earth Planet Sci. Lett., v. 205, p. 295-308.

Crough, S.T., and Jurdy, D.M., 1980, Subducted lithosphere, hotspots, and the geoid: Earth Planet. Sci. Lett., v. 48, p. 15-22.

Cserepes, L., 1993, Effect of depth-dependent viscosity on the pattern of mantle convection: Geophys. Res. Lett., v. 20, p. 2091-2094.

Cserepes, L., and Yuen, D.A., 1997, Dynamical consequences of mid-mantle viscosity stratification on mantle flows with an endothermic phase transition: Geophys. Res. Lett., v. 24, p. 181-184.

Davaille, A., and Vatteville, J., 2005, On the transient nature of mantle plumes: Geophys. Res. Lett., v. 32, Art No. L14309.

Davies, G.F., 1999, Dynamic Earth: Cambridge, Cambridge University Press, 458 p.

Dubuffet, F., Yuen, D.A., and Rainey, E.S.G., 2002, Controlling thermal chaos in the mantle by positive feedback from radiative thermal conductivity: Nonlinear Processes in Geophysics, v. 9, p. 311-323.

Dziewonski, A.M., 1984, Mapping the lower mantle: Determination of lateral heterogeneities in P velocity up to degree and order 6: J. Geophys. Res., v. 89, p. 5929-5952.

Dziewonski, A.M., 2000, Global seismic tomography: past, present and future, in Boschi, E., Ekström, G., and Morelli, A., Problems in geophysics for the new millennium: Bologna, Editrice Compositori, p. 289-350.

Dziewonski, A.M., and Anderson, D.L., 1981, Preliminary reference Earth model: Phys. Earth. Planet. Inter., v. 25, p. 297-356.

Farnetani, C.G., and Samuel, H., 2005, Beyond the thermal plume paradigm: Geophys. Res. Lett., v. 32, Art. No. L07311.

Forte, A.M., and Mitrovica, J.X., 2001, Deep-mantle high-viscosity flow and thermochemical structure inferred from seismic and geodynamic data: Nature, v. 410, p. 1049-1056.

Gerya, T.V., and Yuen, D.A., 2003, Rayleigh-Taylor instabilities from hydration and melting propel 'cold plumes' at subduction zones: Earth Planet. Sci. Lett., v. 212, p. 47-62.

Gibert, B., Schilling, F.R., Gratz, K., and Tommasi, A., 2005, Thermal diffusivity of olivine single crystals and a dunite at high temperature: Evidence for heat transfer by radiation in the upper mantle: Phys. Earth Planet. Inter., v. 151, p. 129-141.

Goldstein, R.J., Chiang, H.D., and See, D.L., 1990, High-Rayleigh number convection in a 
horizontal enclosure: J. Fluid. Mech., v. 213, p. 111-126.

Goncharov, A.F., Struzhkin, V.V., and, Jacobsen, S.D., 2006, Reduced radiative conductivity of low-spin (Mg,Fe)O in the lower mantle: Science, v. 312, p. 1205-1208.

Grand, S.P., van der Hilst, R., and Widiyantoro, S., 1997, Global seismic tomography:

A snapshot of convection in the Earth: GSA Today, v. 7, p. 1-7.

Hansen, U., and Yuen, D.A., 1989, Dynamical influences from thermal-chemical instabilities at the core-mantle boundary: Geophys. Res. Lett., v. 16, p. 629-632.

Hansen, U., and Yuen, D.A., 1994, Effects of depth-dependent thermal expansivity on the interaction of thermal-chemical plumes with a compositional boundary: Phys. Earth Planet. Inter., v. 86, p. 205-221.

Hansen, U., Yuen, D.A., Kroening, S.E., and Larsen, T.B., 1993, Dynamical consequences of depth-dependent thermal expansivity and viscosity on mantle circulations and thermal structure: Phys. Earth Planet. Inter., v. 77, p. 205-223.

Hanyk, L., Moser, J., Yuen, D.A., and Matyska, C., 1995, Time-domain approach for the transient responses in stratified viscoelastic Earth: Geophys. Res. Lett., v. 22, p. 12851288.

Hofmeister, A.M., 1999, Mantle values of thermal conductivity and the geotherm from phonon lifetimes: Science, v. 283, p. 1699-1706.

Hofmeister, A.M., 2005, Dependence of diffusive radiative transfer on grain-size, temperature and Fe-content: implications for mantle processes: J. Geodynamics, v. 40, p. 51-72.

Honda, S., Saito, M., and Nakakuki, T., 2002, Possible existence of small-scale convection under the back arc: Geophys. Res. Lett., v. 29, Art. No. 2043.

Honda, S., Yuen, D.A., Balachandar, S., and Reuteler, D., 1993, Three-dimensional instabilities of mantle convection with multiple phase transitions, Science, v. 259, p. 1308-1311.

Howard, L.N., 1964, Convection at high Rayleigh numbers, in Görtler, H., Proc. 11th Int. Congr. of Appl. Mech., Berlin-Heidelberg-New York, Springer, p. 1109-1115.

Iitaka, T., Hirose, K., Kawamura, K., and Murakami, M., 2004, The elasticity of the $\mathrm{MgSiO}_{3}$ post-perovskite phase in the Earth's lowermost mantle: Nature, v. 430, p. 442-444.

Ishii, M., and Tromp, J., 1999, Normal-mode and free-air gravity constraints on lateral variations in velocity and density of Earth's mantle: Science, v. 285, p. 1231-1236.

Jacobs, M.H.G., van den Berg, A.P., and de Jong, B.H.W.S., 2006, The derivation of thermo-physical properties and phase equilibria of silicate materials from lattice vibrations: Application to convection in the Earth's mantle: Computer Coupling of Phase Diagrams and Thermochemistry, v. 30, p. 131-146.

Jarvis, G.T., and McKenzie, D.P., 1980, Convection in a compressible fluid with infinite Prandtl number: J. Fluid Mech., v. 96, p. 515-583.

Kameyama, M., and Yuen, D.A., 2006, 3-D convection studies on the thermal state in the lower mantle with post-perovskite phase transition: Geophys. Res. Lett., v. 33. Art No. L12S10.

Katsura., T., Yokoshi, S., Shastkiy, A., Okube, M., Fukui, H., Ito, E., Tomioka, N., Sugita, M., Hagiya, K., Kuwata, O., Ohtsuka, K., Nozawa, A., and Funakoshi, K., 2005, Precise determination of thermal expansion coefficient of $\mathrm{MgSiO}_{3}$ perovskite at the top of the lower mantle conditions, in 3rd workshop on Earth's Mantle Composition, Structure, and Phase Transitions: Saint Malo, France, abstract.

Kido, M., and Čadek, O., 1997, Inferences of viscosity from the oceanic geoid: Indication of a low viscosity zone below the 660-km discontinuity: Earth Planet. Sci. Lett., v. 151, p. 125-137. 
King, S.D., and Anderson, D.L., 1995, An alternative mechanism of flood basalt formation: Earth Planet. Sci. Lett., v. 136, p. 269-279.

King, S.D., Ritsema, J., 2000, African hot spot volcanism: Small-scale convection in the upper mantle beneath cratons: Science, v. 290, p. 1137-1140.

Komatisch, D., and Tromp, J., 2002a, Spectral element simulations of global seismic wave propagation - I. Validation: Geophys. J. Int., v. 149, p. 390-412.

Komatisch, D., and Tromp, J., 2002b, Spectral element simulations of global seismic wave propagation - II. Three-dimensional models, oceans, rotation and self-gravitation: Geophys. J. Int., v. 150, p. 303-318.

Korenaga, J., 2005, Firm mantle plumes and the nature of the core-mantle boundary region: Earth Planet Sci. Lett., v. 232, p. 29-37.

Larsen, T.B., and Yuen, D.A., 1997, Fast plumeheads: Temperature-dependent versus nonNewtonian rheology: Geophys. Res. Lett., v. 24, p. 1995-1998.

Lei, J., and Zhao, D., 2005, Global P-wave tomography: On the effect of various mantle and core phases: Phys. Earth Planet. Inter., v. 154, p. 44-69.

Li, L., Brodholt, J.P., Stackhouse, S., Weidner, D.J., Alfredsson, M., and Price, G.D., 2005, Electronic spin state of ferric iron in Al-bearing perovskite in the lower mantle: Geophys. Res. Lett., v. 32, Art. No. L17307.

Lubimova, A.H., 1958, Thermal history of the earth with consideration of the variable thermal conductivity of the mantle: Geophys. J.R. Astr. Soc., v. 1, p. 115-134.

McNamara, A.K., Karato, S.-I., and van Keken, P.E., 2001, Localization of dislocation creep in the lower mantle: implications for the origin of seismic anisotropy: Earth Planet. Sci. Lett., v. 191, p. 85-99.

Mao, W.L., Shen, G., Prakapenka, V.B., Meng, Y., Cambell, A.J., Heinz, D.L., Shu, J., Hemley, R.J., and Mao, H., 2004, Ferromagnesian postperovskite silicates in the D" layer of the Earth: Proc. Nation. Acad. Sci., v. 101, p. 15867-15869.

Mao, W.L., Mao, H., Hu, M., Chow, P., Meng, Y., Shen, G., Prakapenka, V.B., Shu, J., Campbell, A.J., Fei, Y., and Hemley, R.J., 2005, Spin-paired iron in ultra-low velocity zones: Science, submitted.

Mao, W.L., Mao, H., Sturhahn, W., Zhao, J., Prakapenka, V.B., Meng, Y., Shu, J., Fei, Y., and Hemley, R.J., 2006, Iron-rich post-perovskite and the origin of ultralow-velocity zones: Science, v. 312, p. 564-565.

Maruyama, S., 1994, Plume tectonics: J. Geol. Soc. Japan, v. 100, p. 24-49.

Matyska, C., 1995, Axisymmetry of mantle aspherical structures: Geophys. Res. Lett., v. 22, p. 521-524.

Matyska, and Moser, J., 1994, Heating in the D"-layer and the style of mantle convection: Studia Geophys. Geod., v. 38, p. 286-292.

Matyska, C., Moser, J., and Yuen, D.A., 1994, The potential influence of radiative heat transfer on the formation of megaplumes in the lower mantle: Earth Planet. Sci. Lett., v. 125, p. 255-266.

Matyska, C., and Yuen, D.A., 2001, Are mantle plumes adiabatic?: Earth Planet. Sci. Lett., v. 189, p. 165-176.

Matyska, C., and Yuen, D.A., 2002, Bullen's parameter $\eta$ : a link between seismology and geodynamical modelling: Earth Planet. Sci. Lett., v. 198, p. 471-483.

Matyska, C., and Yuen, D.A., 2005, The importance of radiative heat transfer on superplumes in 
the lower mantle with the new post-perovskite phase change: Earth Planet. Sci Lett., v. 234, p. 71-81.

Matyska, C., and Yuen, D.A., 2006, Lower mantle dynamics with the post-perovskite phase change, radiative thermal conductivity, temperature- and depth-dependent viscosity: Phys. Earth Planet. Inter., v. 154, p. 196-207.

Matyska, C., Yuen, D.A., Breuer, D., and Spohn, T., 1998, Symmetries of volcanic distributions on Mars and Earth and their mantle plume dynamics: J. Geophys. Res., v. 103, p. 2858728597.

Meneveau, C., and Sreenivasan, K.R., 1991, The multifractal nature of turbulent energydissipation: J. Fluid Mech., v. 224, p. 429-484.

Mitrovica, J.X., and Forte, A.M., 2004, A new inference of mantle viscosity based upon joint inversion of convection and glacial isostatic adjustment data: Earth Planet. Sci. Lett., v. 225, p. 177-189.

Monnereau, M., and Yuen, D.A., 2002, How flat is the lower-mantle temperature gradient?: Earth Planet. Sci. Lett., v. 202, p. 171-183.

Montelli, R., Nolet, G., Dahlen, F.A., Masters, G., Engdahl, E.R., and Hung, S.-H., 2004, Finitefrequency tomography reveals a variety of plumes in the mantle: Science, v. 303, p. 338343.

Morgan, W.J., 1971, Convection plumes in the lower mantle: Nature, v. 230, p. 42-43.

Murakami, M., Hirose, K., Kawamura, K., Sata, N., and Ohishi, Y., 2004, Post-perovskite phase transition in $\mathrm{MgSiO}_{3}$ : Science, v. 304, p. 855-858.

Nakagawa, T., and Tackley, P.J., 2005, The interaction between the post-perovskite phase change and a thermo-chemical boundary layer near the core-mantle boundary: Earth Planet Sci. Lett., v. 238, p. 204-216.

Naliboff, J.B., and Kellogg, L.H., 2006, Dynamic effects of a step-wise increase in thermal conductivity and viscosity in the lowermost mantle: Geophys. Res. Lett., v. 33, Art. No. L12S09.

Ni, S.D., and Helmberger, D.V., 2003, Seismological constraints on the South African superplume; could be the oldest distinct structure on Earth: Earth Planet. Sci. Lett., v. 206, p. 119-131.

Oganov, A.R., and Ono, S., 2004, Theoretical and experimental evidence for a post-perovskite phase of $\mathrm{MgSiO}_{3}$ in Earth's D" layer: Nature, v. 430, p. 445-448.

Ogura, Y., and, Phillips, N.A., 1962, Scale analysis of deep and shallow convection in the atmosphere: J. Atmosph. Sci., v. 19, p. 173-179.

Olson, P.L., and Singer, H.A., 1985, Creeping Plumes: J. Fluid Mech., v. 158, p. 511-538.

Pilidou, S., Priestley, K., Debayle, E., and Gudmundsson, O., 2005, Rayleigh wave tomography in the North Atlantic: High resolution images of the Iceland, Azores and Eifel mantle plumes: Lithos, v. 79, p. 453-474.

Ranalli, G., 1995, Rheology of the Earth, London, Chapman and Hall, 413 p.

Ricard, Y., Fleitout, L., and Froidevaux, C., 1984, Geoid heights and lithospheric stresses for a dynamic Earth: Annales Geophys., v. 2, p. 267-286.

Ricard, Y., and Wuming, B., 1991, Inferring viscosity and the 3-D density structure of the mantle from geoid, topography and plate velocities: Geophys. J. Int., v. 105, p. 561-572.

Richards, M.A., and Hager, B.H., 1988, Dynamically supported geoid highs over hotspots: Observations and theory: J. Geophys. Res., v. 93, p. 7690-7708.

Ritsema, J., van Heijst, H.J., and Woodhouse, J.H., 1999, Complex shear wave velocity structure 
imaged beneath Africa and Island: Science, v. 286, p. 1925-1928.

Schubert, G., Turcotte, D.L., and Olson, P., 2001, Mantle convection in the Earth and planets: Cambridge, Cambridge University Press, $940 \mathrm{p}$.

Solomatov, V.S., 1996, Can hotter mantle have a larger viscosity?: Geophys. Res. Lett., v. 23, p. 937-940.

Solomatov, V.S., 2001, Grain size-dependent viscosity convection and the thermal evolution of the Earth: Earth Planet. Sci. Lett., v. 191, p. 203-212.

Spiegel, E.A., and Veronis, G., 1960, On the Boussinesq approximation for a compressible fluid: Astrophys. J., v. 131, p. 442-447.

Stefanick, M., and Jurdy, D.M., 1984, The distribution of hot spots: J. Geophys. Res., v. 89, p. 9919-9925.

Steinbach, V., and Yuen, D.A., 1994, Melting instabilities in the transition zone: Earth Planet. Sci. Lett., v. 127, p. 67-75.

Su, W.-J., and Dziewonski, A.M., 1991, Predominance of long-wavelength heterogeneity in the mantle: Nature, v. 352, p. 121-126.

Tackley, P.J., 1998, Three-dimensional simulations of mantle convection with a thermochemical CMB boundary layer: D"?, in Gurnis, M. et al., The core-mantle boundary region: Washington, American Geophysical Union, p. 231-253.

Tan, E., and Gurnis, M., 2005, Metastable superplumes and mantle compressibility: Geophys. Res. Lett., v. 32, Art No. L20307.

Thoraval, C., Tommasi, A., and Doin, M.-P., 2006, Plume-lithosphere interaction beneath a fast moving plate: Geophys. Res. Lett., v. 33, Art. No. L01301.

Trampert, J., Deschamps, F., Resovsky, J., and Yuen, D.A., 2004, Probabilistic tomography maps chemical heterogeneities throughout the lower mantle: Science, v. 306, p. 853-856.

Tsuchiya, T., Tsuchiya, J., Umemoto, K., and Wentzcovitch, R.M., 2004, Phase transition in $\mathrm{MgSiO}_{3}$ perovskite in the earth's lower mantle: Earth Planet Sci. Lett., v. 224, p. 241-248.

Tsuchiya, J., Tsuchiya, T., and Wentzcovitch, R.M., 2005, Vibrational and thermodynamic properties of $\mathrm{MgSiO}_{3}$ post-perovskite: J. Geophys. Res., v. 110, Art. No. B02204.

Turcotte, D.L., 1992, Fractals and chaos in geology and geophysics: Cambridge, Cambridge Univ. Press, $221 \mathrm{p}$.

Turcotte, D.L., and Schubert, G., 2002, Geodynamics: Cambridge, Cambridge University Press, Second edition, $456 \mathrm{p}$.

van den Berg, A.P., Yuen, D.A., and Steinbach, V., 2001, The effects of variable thermal conductivity on mantle heat-transfer: Geophys. Res. Lett., v. 28, p. 875-878.

van den Berg, A.P., Yuen, D.A., and Allwardt, J.R., 2002, Non-linear effects from variable thermal conductivity and mantle internal heating: implications for massive melting and secular cooling of the mantle: Phys. Earth Planet. Inter., v. 129, p. 359-375.

van Keken, P.E., Yuen, D.A., and, van den Berg, A.P., 1992, Pulsating diapiric flows: consequences of vertical variations of mantle creep laws: Earth Planet. Sci. Lett., v. 112, p. 179-194.

Whitehead, J.A., and Luther, D.S., 1975, Dynamics of laboratory diapir and plume models: J. Geophys. Res., v. 80, p. 705-717.

Yuen, D.A., Hansen, U., Zhao, W., Vincent, A.P., and Malevsky, A.V., 1993, Hard turbulent thermal convection and thermal evolution of the mantle: J. Geophys. Res., v. 98, p. 53555373.

Zaman, K.B., and Hussain, A.K., 1981, Taylor hypothesis and large-scale coherent structures: 
J. Fluid Mech., v. 112, p. 379-396.

Zhao, D., 2001, Seismic structure and origin of hotspots and mantle plumes: Earth Planet. Sci. Lett., v. 192, p. 251-265.

Zhao, D., 2004, Global tomographic images of mantle plumes and subducting slabs: insight into deep Earth dynamics: Phys. Earth Planet. Inter., v. 146, p. 3-34.

Zhao, W., and Yuen, D.A., 1987, The effects of adiabatic and viscous heatings on plumes: Geophys. Res. Lett., v. 14, p. 1223-1227.

Zhou, Y., Dahlen, F.A., and Nolet, G., 2004, Three-dimensional sensitivity kernels for surface wave observables: Geophys. J. Int., v. 158, p. 142-160.

Zhou, Y., Dahlen, F.A. , Nolet, G., and Laske, G., 2005, Finite-frequency effects in global surface-wave tomography: Geophys. J. Int., v. 163, p. 1087-1111. 


\section{FIGURE CAPTIONS}

Fig. 1 The depth-dependence of dimensionless thermal expansivity, see eqn. (36) for the "old thermal expansivity"' profile and eqns. (37), (38) for the "new thermal expansivity" profile. The remaining curve denotes the decadic logarithm of the depth-dependent part of the dimensionless viscosity, see eqn. (39).

Fig. 2 Typical snapshots of the temperature field for a long time scale $\left(\mathrm{O}\left(10^{9} \mathrm{yr}\right)\right)$. No phase changes were included. The red color represents the maximum temperature while the dark blue color denotes the minimum temperature. The medium temperature is given by the cold to warm transition from the green to yellow color. The panels show the effect of a change of the surface Rayleigh number from $10^{6}$ to $10^{7}$ in the two top panels and inclusion of the depthdependence of viscosity or thermal expansivity in the remaining panels, see Fig. 1 and eqn. (36) for the "old" thermal expansivity, eqns. (37), (38) for the "new thermal expansivity, eqn. (39) for the depth-dependent viscosity.

Fig. 3 The sketch showing the major geophysical features of the complex models used for generating multiscale plumes.

Fig. 4 Typical snapshots of the temperature field for a long time scale. The "old" depthdependent thermal expansivity according to formula (36) was considered. Viscosity was both the depth- and temperature-dependent, see eqns. (39)-(41). An endothermic phase change with $P=-0.15$ at the depth of $670 \mathrm{~km}$ and an exothermic phase change with $P=0.10$ at the depth of $2650 \mathrm{~km}$ were included. Thermal conductivity was considered in the form (42), where $g(z)=0$ (no radiative heat transfer) in the top panel and $g(z)=10$ (strong global radiative heat transfer) in the last panel. In the remaining panels, radiative heat transfer is considered only below the depth $2650 \mathrm{~km}$ with $g$ equal to 2,5 and 10 .

Fig. 5 Residual temperature, the difference between the local temperature and horizontally averaged temperature for the cases shown in Fig. 4.

Fig. 6 Streamlines of the model flow for the cases shown in Fig. 4. The streamfunction is equal to zero on all sides of the box and the contour interval of streamlines is 50 in dimensionless units. The contour interval is kept the same in all panels. The solid lines display the zero and negative values and the dashed lines show the positive values of the streamfunction.

Fig. 7 Decadic logarithm of dimensionless viscosity for the cases shown in Fig. 4. Dashed lines show negative values and solid lines mark zero and positive values. The contour interval is 0.5 in all panels.

Fig. 8 Decadic logarithm of dimensionless shear heating for the cases shown in Fig. 4.

Fig. 9 Typical snapshots of the temperature field for a long time scale. The "new" depthdependent thermal expansivity according to eqns. (37), (38) was considered. Viscosity was both the depth- and temperature-dependent, see eqns. (39)-(41). An endothermic phase change

with $P=-0.08$ at the depth of $670 \mathrm{~km}$ and an exothermic phase change with $P=0.05$ at the depth of $2650 \mathrm{~km}$ were included. Thermal conductivity was considered in the form (42), where $g(z)=0$ (no radiative heat transfer) in the top panel and $g(z)=10$ (strong global radiative heat transfer) in the last panel. In the remaining panels, radiative heat transfer is considered only below the depth $2650 \mathrm{~km}$ with $g$ equal to 2,5 and 10 . We used a periodic color scale, i.e., dark blue below the transition zone shows the places, where dimensionless temperatures are slightly higher than 1 , which corresponds to the temperature at the core-mantle boundary.

Fig. 10 Residual temperature, the difference between the local temperature and horizontally averaged temperature for the cases shown in Fig. 9. 
Fig. 11 Streamlines of the model flow for the cases shown in Fig. 9. The streamfunction is equal to zero on all sides of the box and the contour interval of streamlines is 50 in dimensionless units. The contour interval is kept the same in all panels. The solid lines display the zero and negative values and the dashed lines show the positive values of the streamfunction.

Fig. 12 Decadic logarithm of dimensionless viscosity for the cases shown in Fig. 9. Dashed lines show negative values and solid lines mark zero and positive values. The contour interval is 0.5 in all panels.

Fig. 13 Decadic logarithm of dimensionless shear heating for the cases shown in Fig. 9. We note that the amount of radiogenic heating due to chondritic abundance is about 10 .

Fig. 14 Zoom of the upper mantle plumes. Left (right) column is for the cases shown in the left (right) part of Fig. 4. Vertical range is about $1200 \mathrm{~km}$ and the horizontal length corresponds to about $7200 \mathrm{~km}$. Difference between the local temperature and horizontally averaged temperature is displayed.

Fig. 15 Zoom of the upper mantle plumes. Left (right) column is for the cases shown in the left (right) part of Fig. 9. Vertical range is about $1200 \mathrm{~km}$ and the horizontal length corresponds to about $7200 \mathrm{~km}$. Difference between the local temperature and horizontally averaged temperature is displayed.

Fig. 16 Time-series of snapshots of the upper-mantle plumes, where the depth-dependent thermal expansivity according to eqns. (37), (38) was considered, an endothermic phase change with $P=-0.08$ at the depth of $670 \mathrm{~km}$ and an exothermic phase change with $P=0.05$ at the depth of $2650 \mathrm{~km}$ were included, thermal conductivity was considered in the form (42), where radiative heat transfer is considered only below the depth $2650 \mathrm{~km}$ with $g$ equal to 10 . Vertical range is about $1100 \mathrm{~km}$ and the horizontal length corresponds to about $5300 \mathrm{~km}$.

Dimensionless time differences between two subsequent snapshots is 0.00005 , corresponding to around 15 Myr. We used a periodic color scale, i.e., dark blue below the transition zone shows the places, where dimensionless temperatures are slightly higher than 1 .

Fig. 17 Sketch showing the multiscale nature of mantle plumes, which involves the creation of the lower mantle superplume from the D" layer and generation of the upper mantle plumes from the low viscosity layer below the $670 \mathrm{~km}$. 


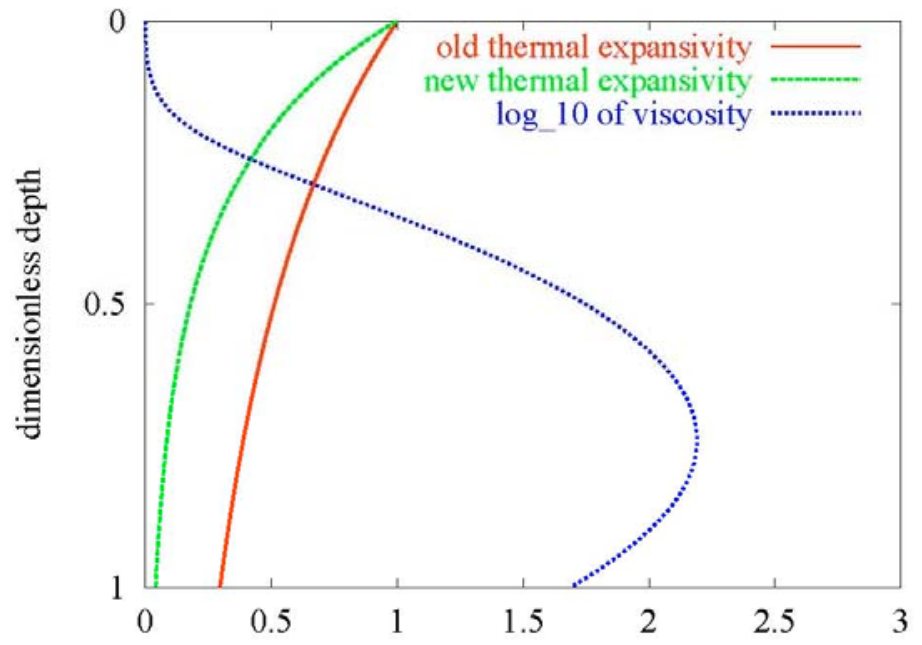

Fig. 1 
No phase changes, $k=1, \quad \mathrm{Di}=0.5, \mathrm{R}=3$

$R a=10^{6}$, constant viscosity, constant thermal expansivity

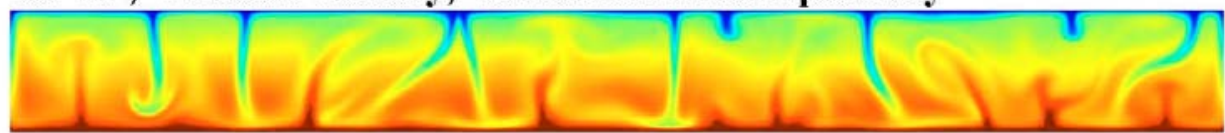

$R a=10^{7}$, constant viscosity, constant thermal expansivity

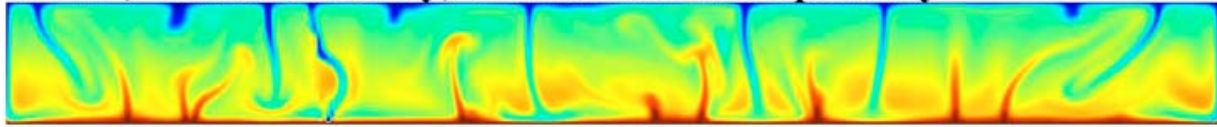

$\mathrm{Ra}_{\mathrm{s}}=10^{7}$, depth-dependent viscosity, constant thermal expansivity

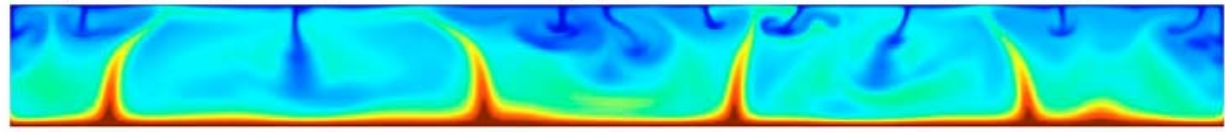

$\mathrm{Ra}_{\mathrm{S}}=10^{7}$, constant viscosity, old depth-dependent thermal expansivity

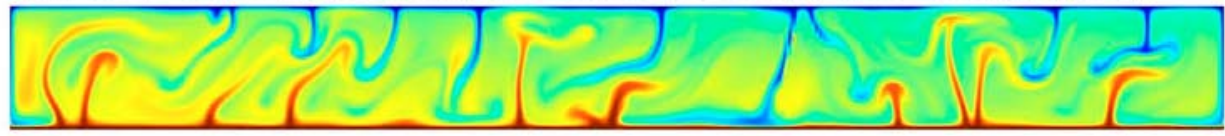

$\mathrm{Ra}_{\mathrm{S}}=10^{7}$, constant viscosity, new depth-dependent thermal expansivity
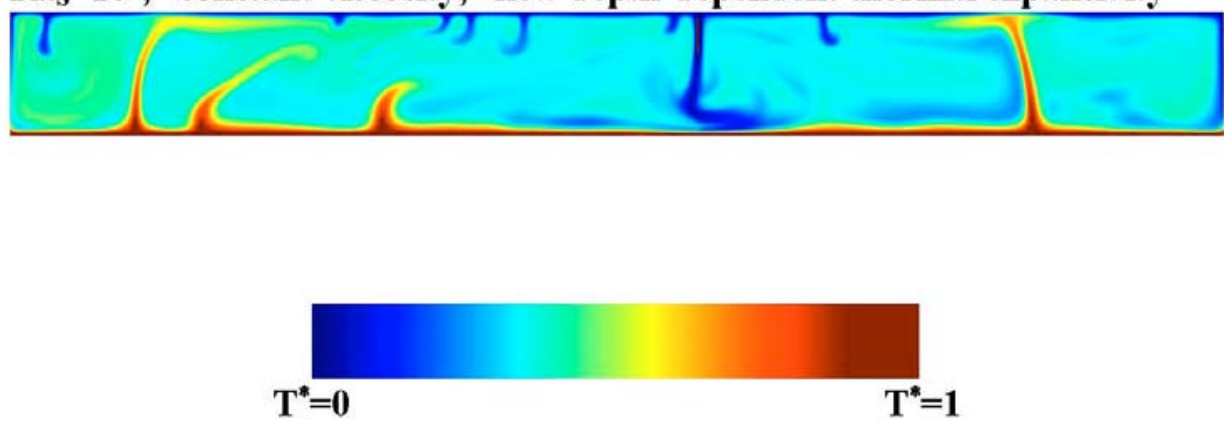

Fig. 2 


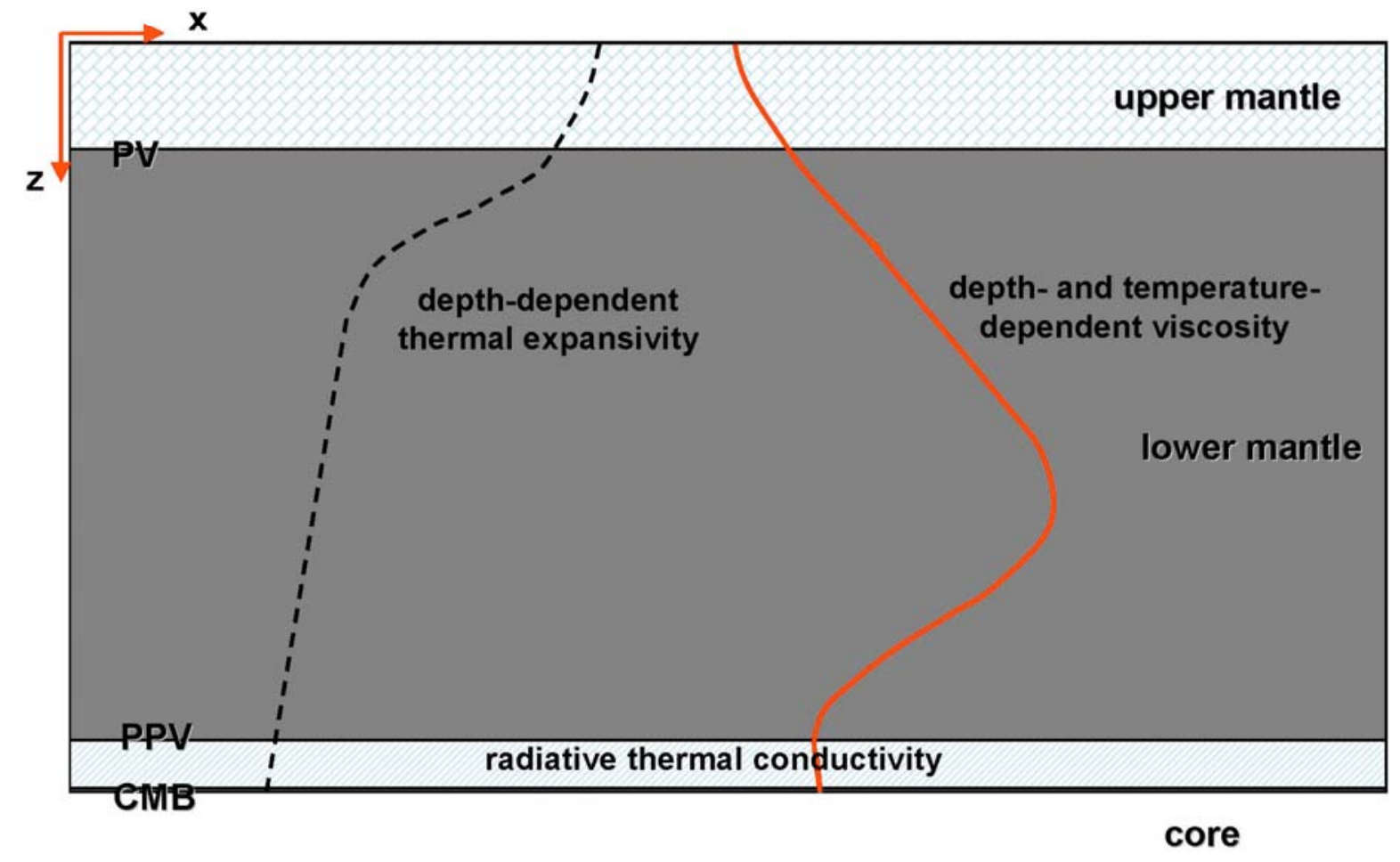

Fig. 3 


$$
\text { Old thermal expansivity } \quad P_{670}=-\mathbf{0 . 1 5} \quad P_{D^{*}}=0.10
$$

$\mathbf{k}=\mathbf{1}$

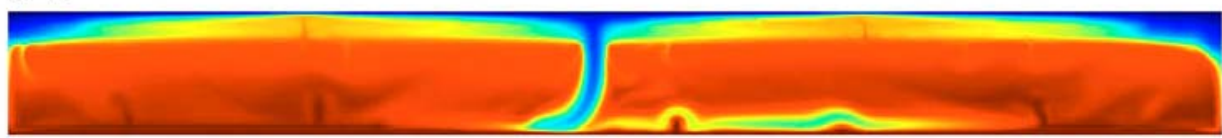

$k=1+2\left(T_{0}+T\right)^{3}$ in $D^{\prime \prime} \quad k=1$ above $D "$

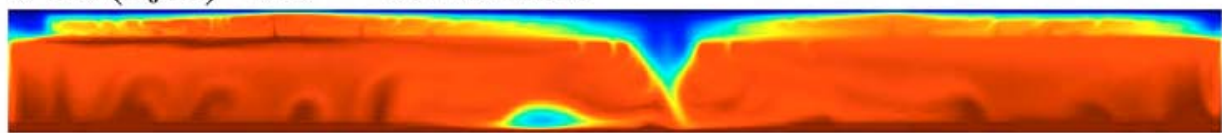

$k=1+5\left(T_{0}+T\right)^{3}$ in $D^{\prime \prime} \quad k=1$ above $D^{\prime \prime}$

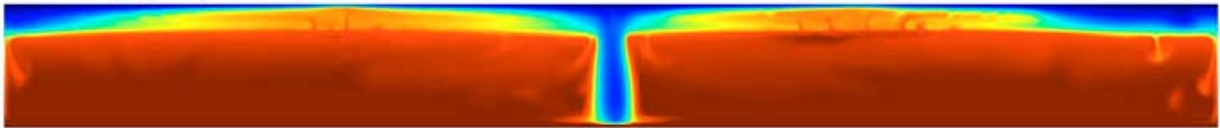

$k=1+10\left(T_{0}+T\right)^{3}$ in $D^{\prime \prime} \quad k=1$ above $D ”$

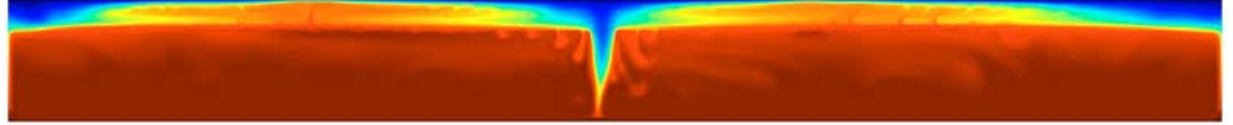

$k=1+10\left(T_{0}+T\right)^{3}$ in the whole mantle
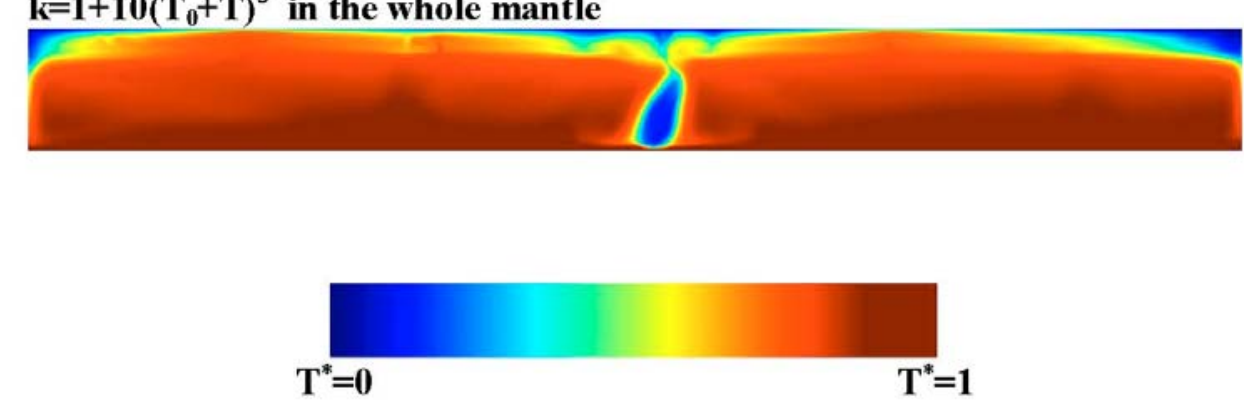

Fig. 4 


$$
\text { Old thermal expansivity } \quad P_{670}=-\mathbf{0 . 1 5} \quad P_{D^{*}}=0.10
$$

$k=1$

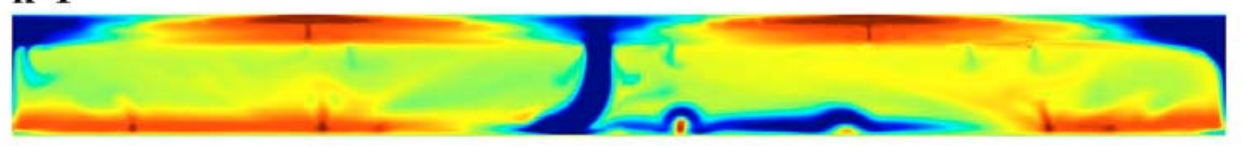

$$
k=1+2\left(T_{0}+T\right)^{3} \text { in } D^{\prime \prime} \quad k=1 \text { above } D^{\prime \prime}
$$

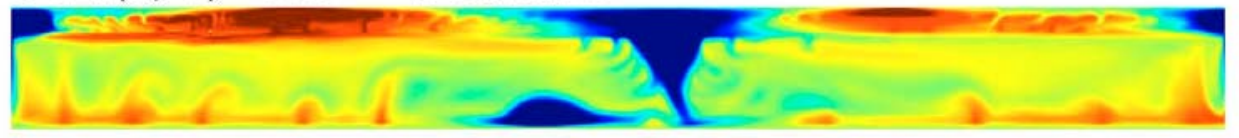

$$
k=1+5\left(T_{0}+T\right)^{3} \quad \text { in } D{ }^{\prime} \quad k=1 \text { above } D^{\prime \prime}
$$

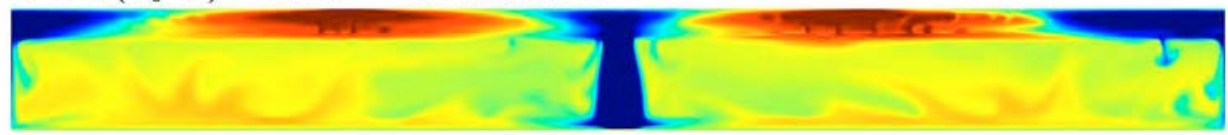

$k=1+10\left(T_{0}+T\right)^{3}$ in $D^{\prime \prime} \quad k=1$ above $D "$

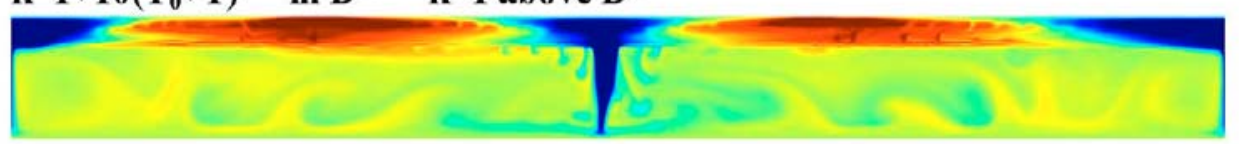

$k=1+10\left(T_{0}+T\right)^{3}$ in the whole mantle
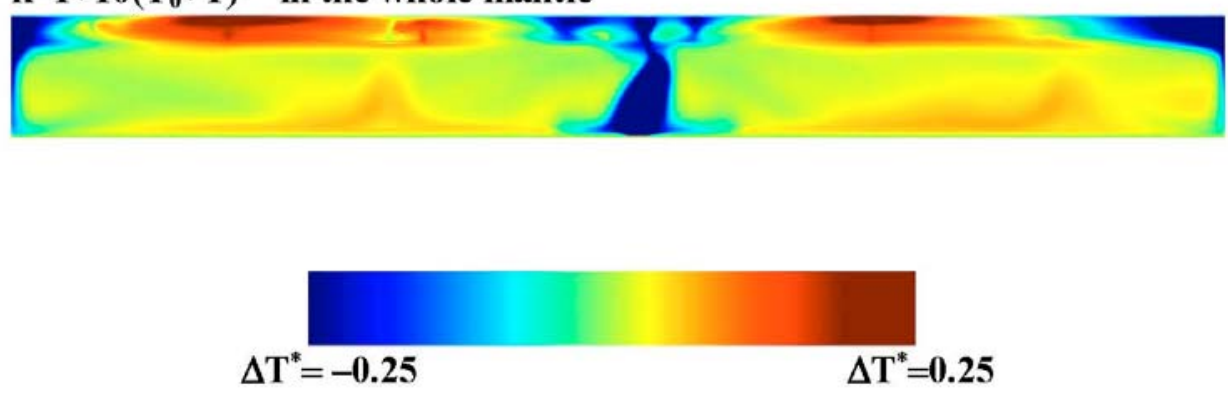

Fig. 5 
Old thermal expansivity $\quad \mathrm{P}_{670}=-\mathbf{0 . 1 5} \quad \mathrm{P}_{\mathrm{D}^{\prime \prime}}=\mathbf{0 . 1 0}$
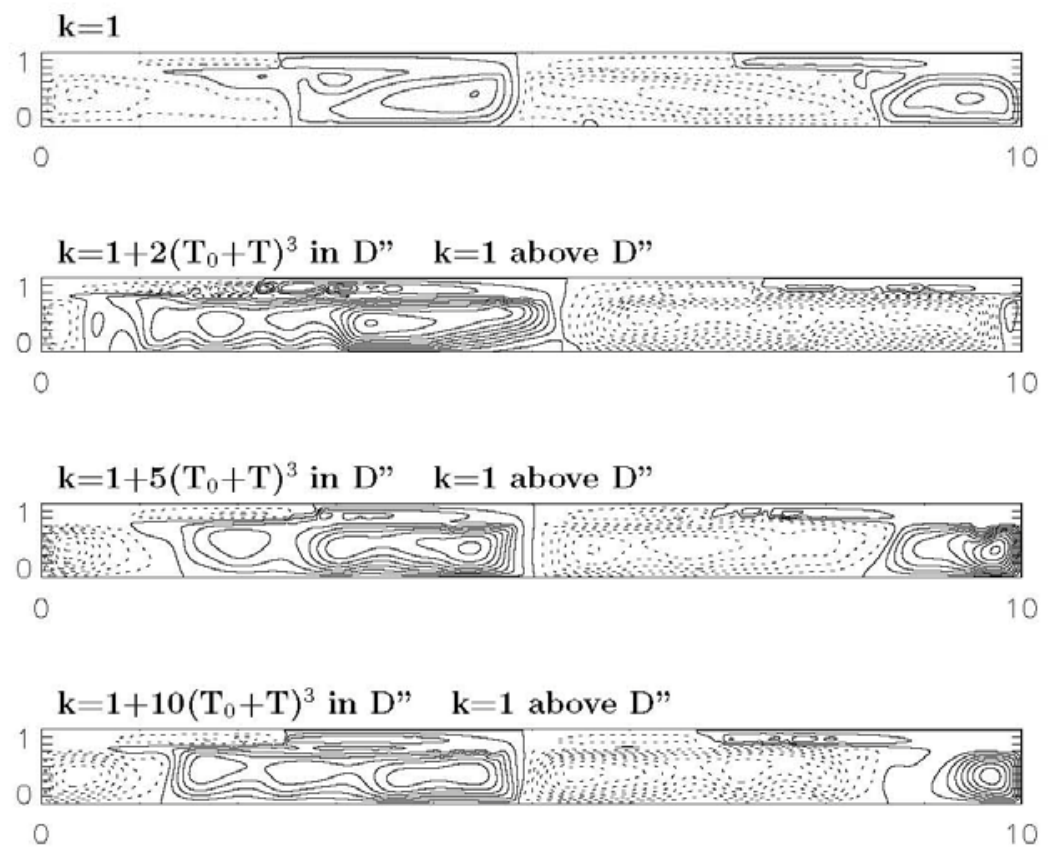

$k=1+10\left(T_{0}+T\right)^{3}$ in the whole mantle

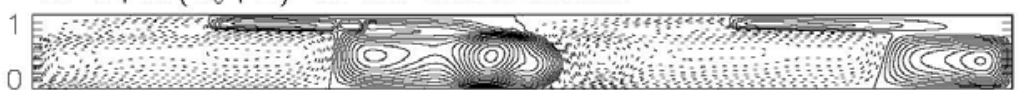

0

Fig. 6 
Old thermal expansivity $\quad \mathrm{P}_{670}=-0.15 \quad \mathrm{P}_{\mathrm{D}^{\prime \prime}}=0.10$
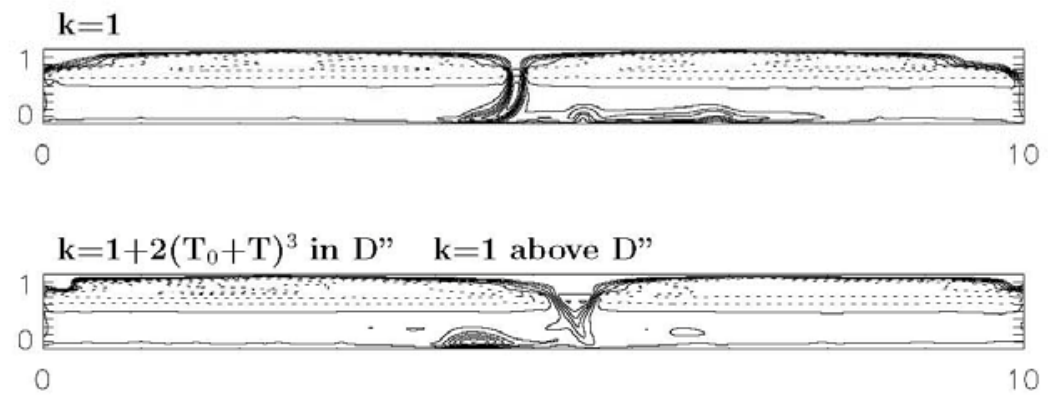

$\mathbf{k}=1+5\left(\mathrm{~T}_{0}+\mathrm{T}\right)^{3}$ in D" $\mathbf{k}=1$ above $\mathrm{D} "$

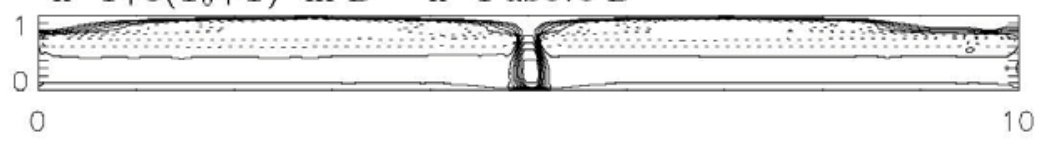

$\mathbf{k}=1+\mathbf{1 0}\left(\mathrm{T}_{0}+\mathrm{T}\right)^{3}$ in $\mathrm{D}^{\prime \prime} \quad \mathbf{k}=\mathbf{1}$ above $\mathrm{D}^{\prime \prime}$

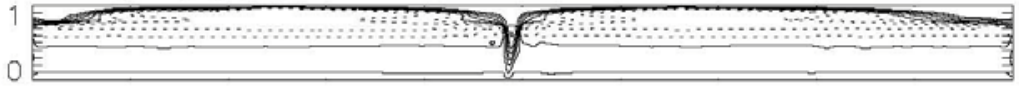

0

$k=1+10\left(T_{0}+T\right)^{3}$ in the whole mantle

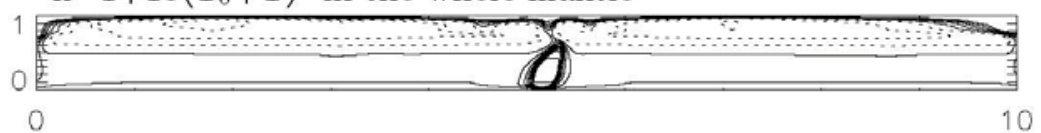

Fig. 7 


\section{Decadic logarithm of shear heating}

$$
\text { Old thermal expansivity } \quad P_{670}=-0.15 \quad P_{D}=0.10
$$
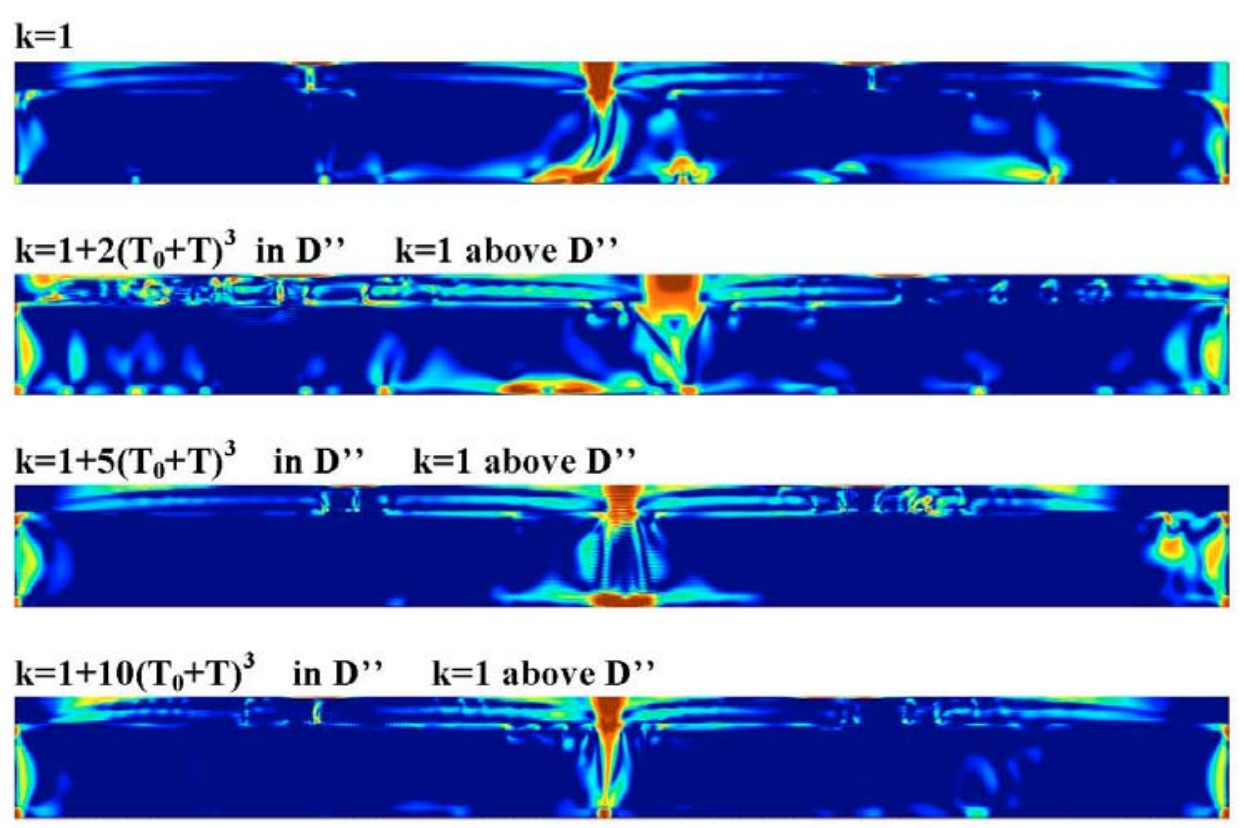

$k=1+10\left(T_{0}+T\right)^{3}$ in the whole mantle
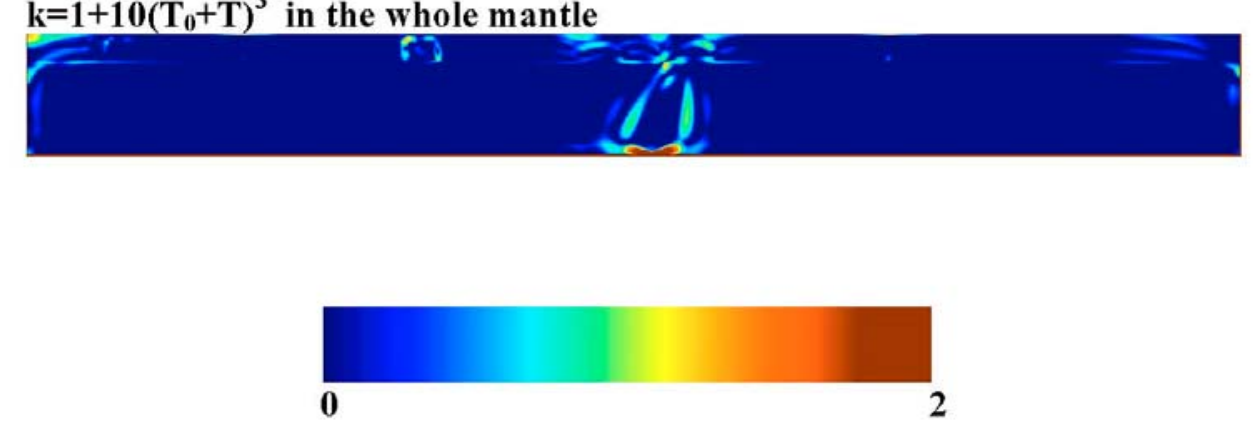

Fig. 8 


$$
\text { New thermal expansivity } \quad P_{670}=-0.08 \quad P_{D},=0.05
$$

$k=1$
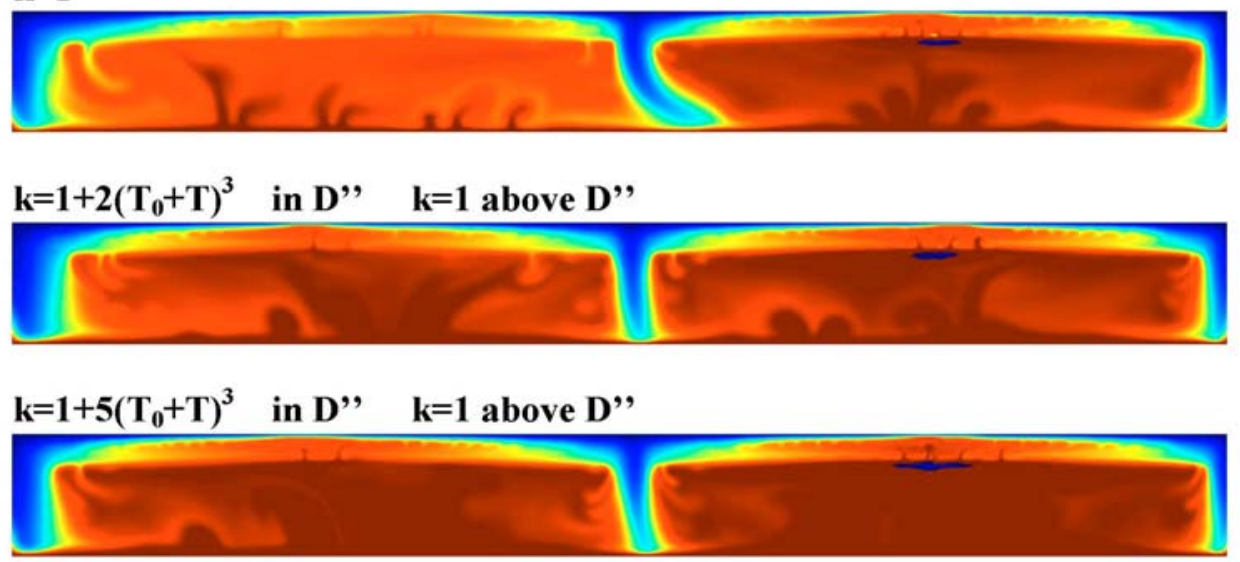

$k=1+10\left(T_{0}+T\right)^{3}$ in D', $k=1$ above $D^{\prime \prime}$

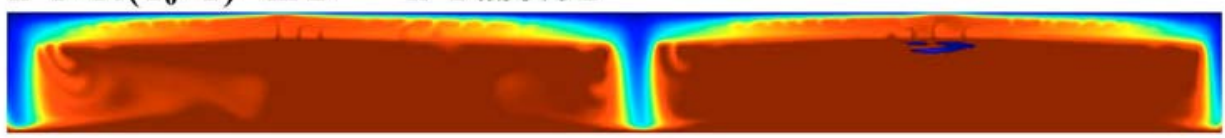

$k=1+10\left(T_{0}+T\right)^{3}$ in the whole mantle
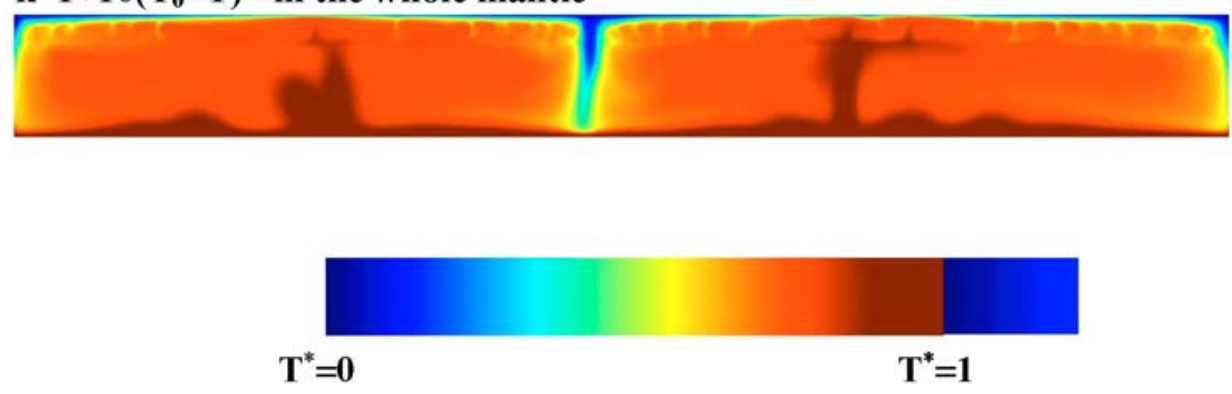

Fig. 9 


$$
\text { New thermal expansivity } \quad P_{670}=-0.08 \quad P_{D}{ }^{*}=0.05
$$

$k=1$

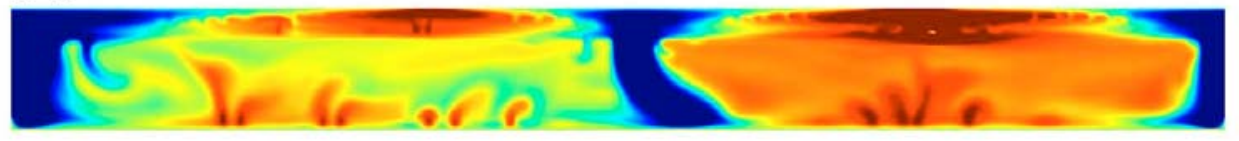

$k=1+2\left(T_{0}+T\right)^{3}$ in $D^{\prime}, \quad k=1$ above $D^{\prime}$,

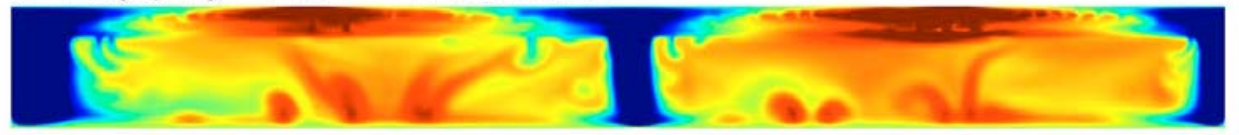

$k=1+5\left(T_{0}+T\right)^{3}$ in D', $k=1$ above $D^{\prime \prime}$

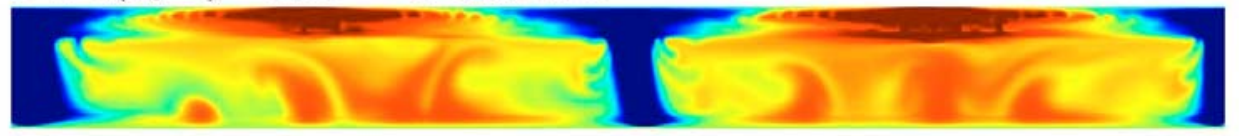

$k=1+10\left(T_{0}+T\right)^{3}$ in $D^{\prime \prime} \quad k=1$ above $D "$

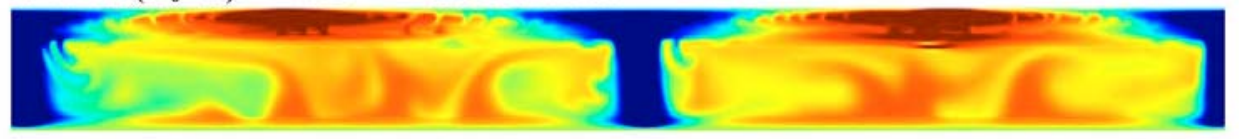

$k=1+10\left(T_{0}+T\right)^{3}$ in the whole mantle
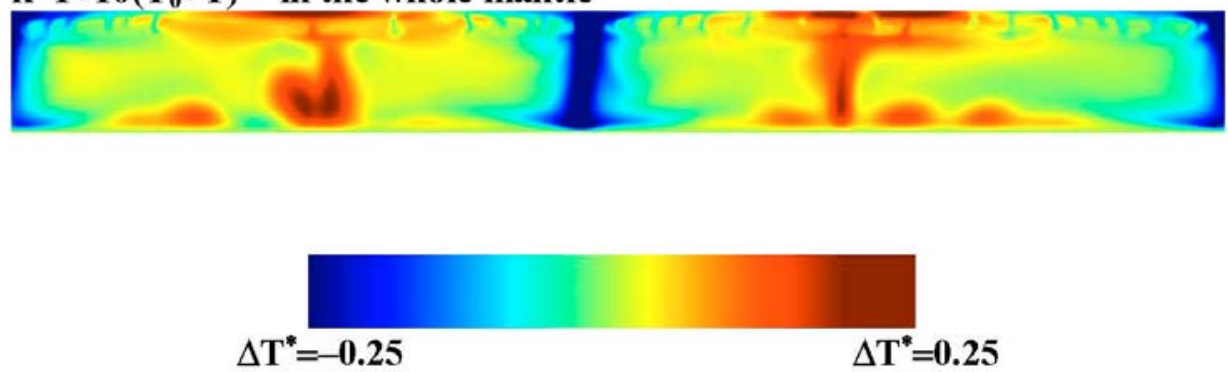

Fig. 10 
New thermal expansivity $\quad \mathrm{P}_{670}=-0.08 \quad \mathrm{P}_{\mathrm{D}^{\prime \prime}}=0.05$
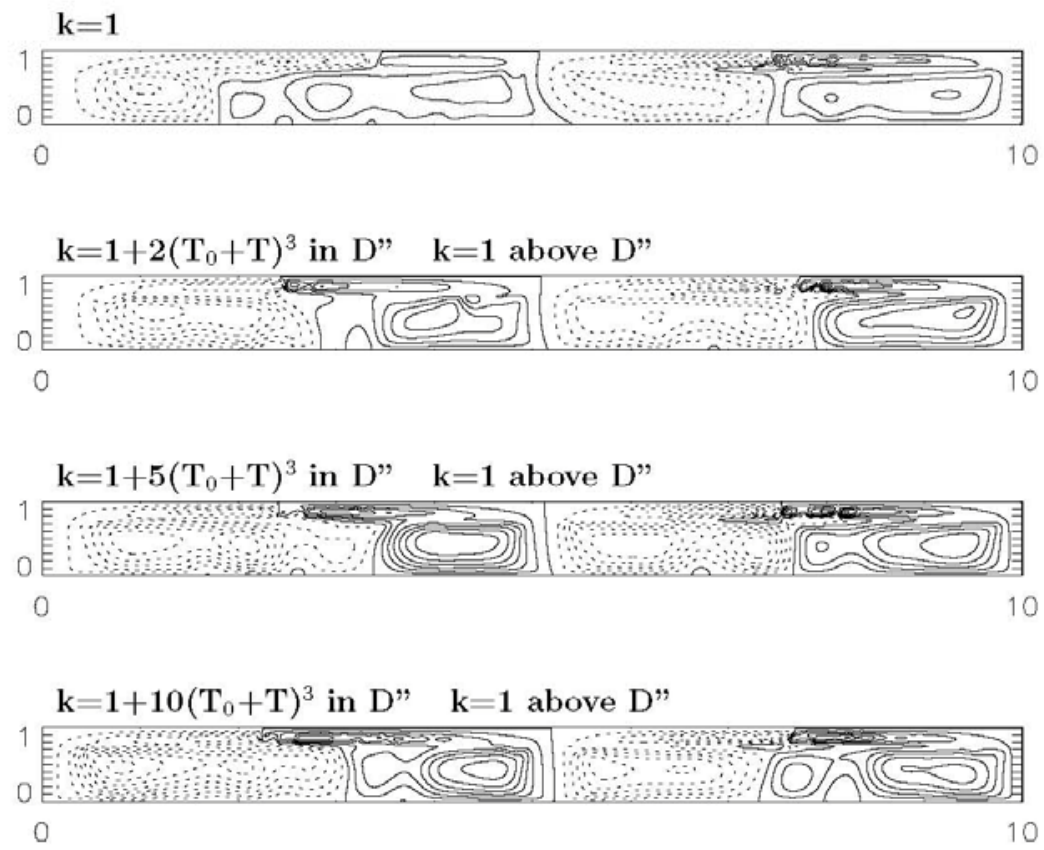

$k=1+10\left(T_{0}+T\right)^{3}$ in the whole mantle

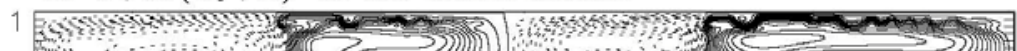

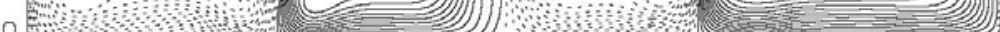

0

Fig. 11 
New thermal expansivity $\quad \mathrm{P}_{670}=-0.08 \quad \mathrm{P}_{\mathrm{D}^{\prime \prime}}=0.05$
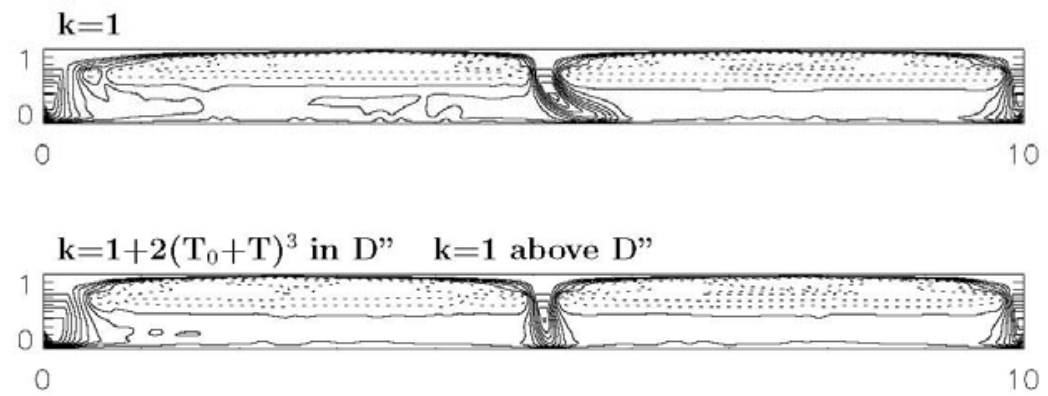

$\mathbf{k}=1+5\left(\mathrm{~T}_{0}+\mathrm{T}\right)^{3}$ in $\mathrm{D} " \mathbf{k}=1$ above $\mathrm{D} "$

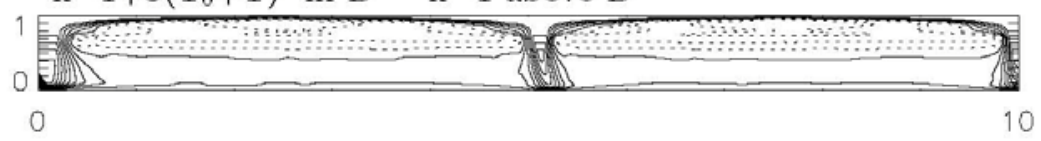

$\mathbf{k}=1+10\left(\mathrm{~T}_{0}+\mathrm{T}\right)^{3}$ in $\mathrm{D} " \quad \mathbf{k}=1$ above $\mathrm{D} "$

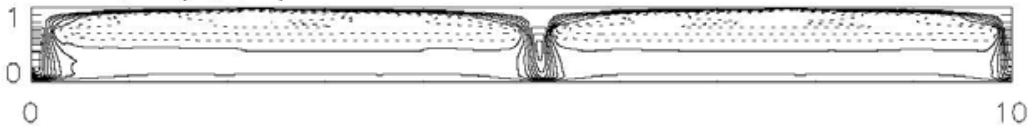

$k=1+10\left(T_{0}+T\right)^{3}$ in the whole mantle

1

0

Fig. 12 
Decadic logarithm of shear heating

New thermal expansivity $\quad P_{670}=\mathbf{- 0 . 0 8} \quad P_{D}$ " $=0.05$

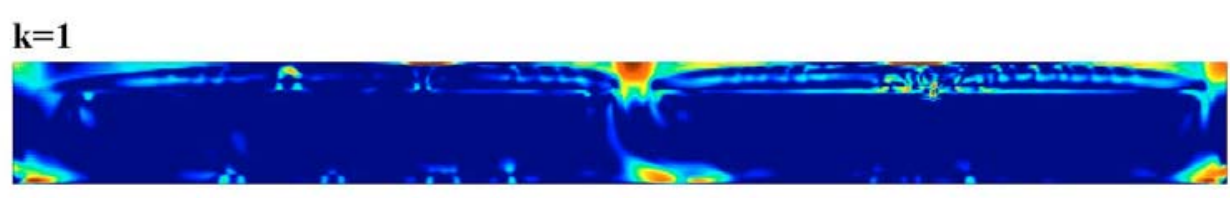

$k=1+2\left(T_{0}+T\right)^{3}$ in D', $k=1$ above $D^{\prime \prime}$
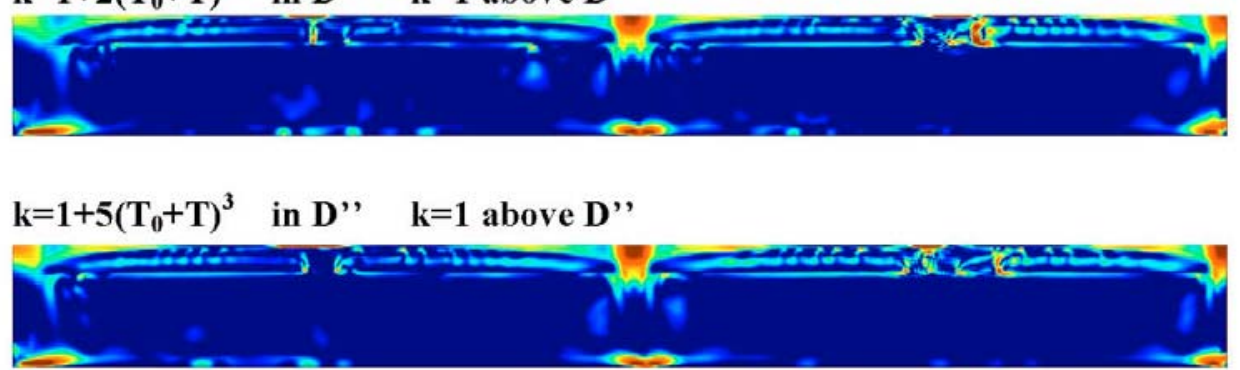

$k=1+10\left(T_{0}+T\right)^{3}$ in $D^{\prime \prime} \quad k=1$ above $D^{\prime \prime}$

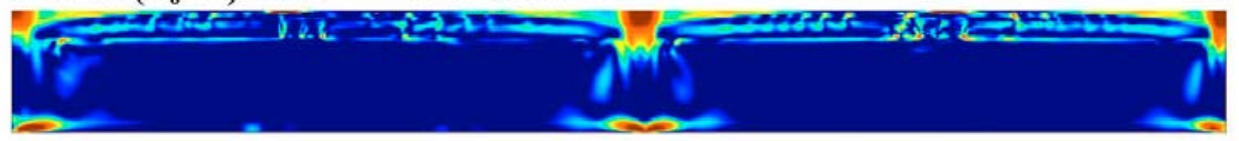

$k=1+10\left(T_{0}+T\right)^{3}$ in the whole mantle

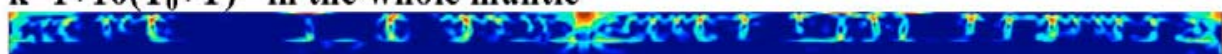

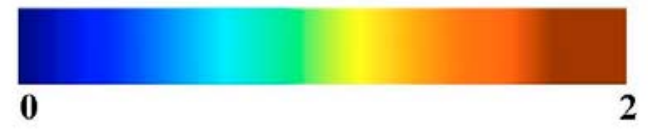

Fig. 13 


$$
\text { Old thermal expansivity } \quad P_{670}=-0.15 \quad P_{D}=0.10
$$

$\mathbf{k}=1$

$k=1+2\left(T_{0}+T\right)^{3} \quad$ in D', $k=1$ above $D^{\prime}$,

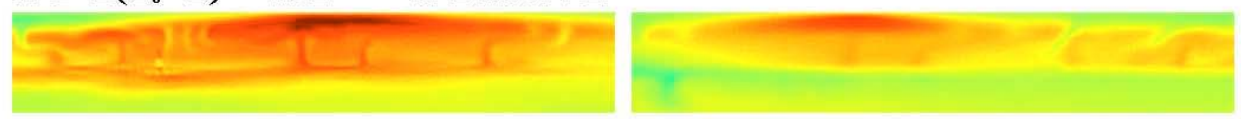

$k=1+5\left(T_{0}+T\right)^{3} \quad$ in $D^{\prime \prime} \quad k=1$ above $D \prime$

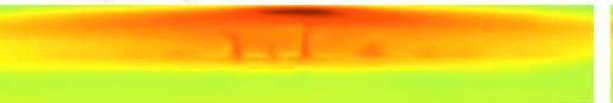

$k=1+10\left(T_{0}+T\right)^{3} \quad$ in $D^{\prime}, \quad k=1$ above $D^{\prime}$,

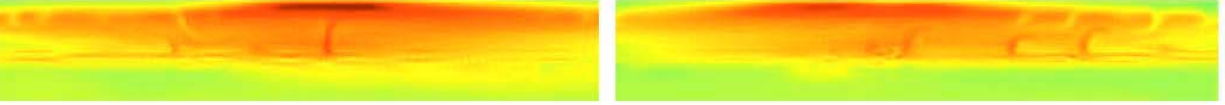

$k=1+10\left(T_{0}+T\right)^{3}$ in the whole mantle
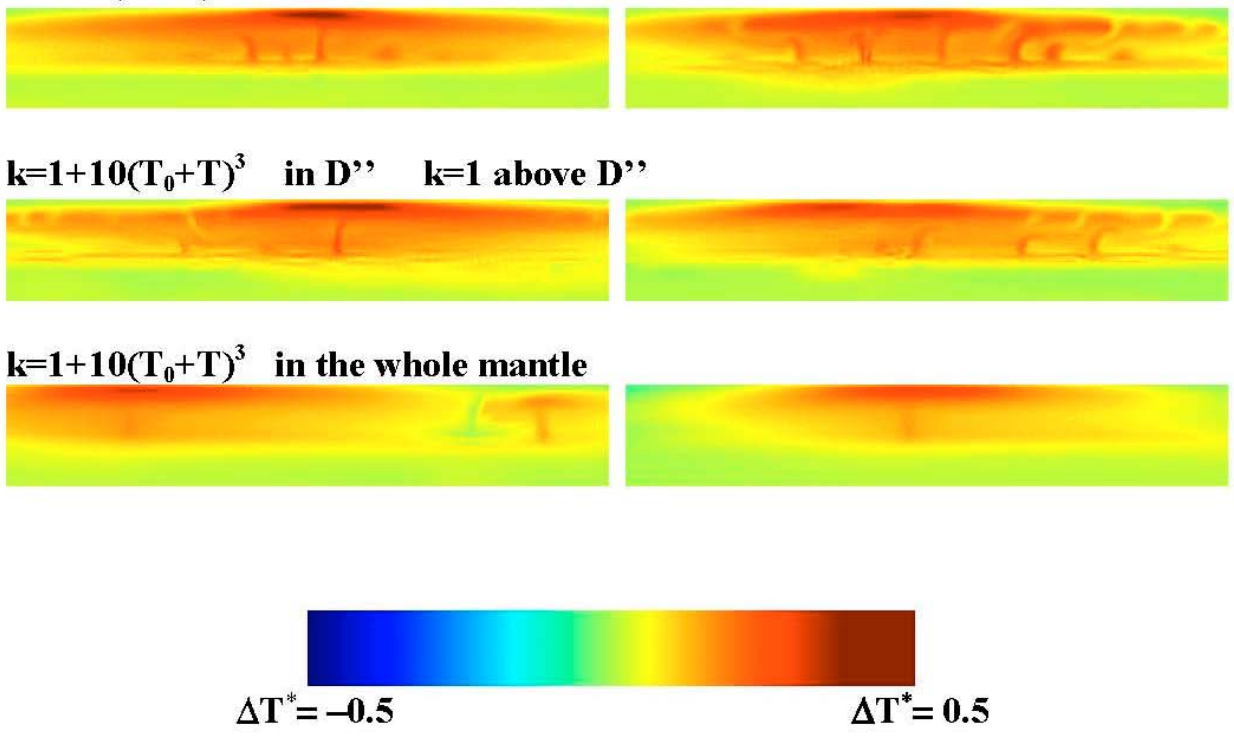

Fig. 14 


$$
\text { New thermal expansivity } \quad P_{670}=-0.08 \quad P_{D},=0.05
$$

$k=1$

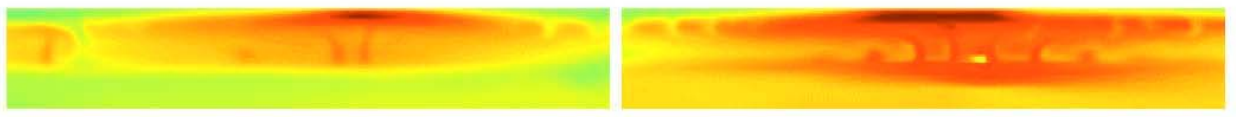

$k=1+2\left(T_{0}+T\right)^{3} \quad$ in $D^{\prime}, \quad k=1$ above $D^{\prime \prime}$

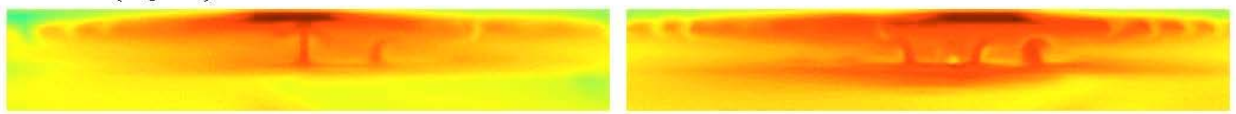

$k=1+5\left(T_{0}+T\right)^{3}$ in $D^{\prime}, \quad k=1$ above $D^{\prime}$

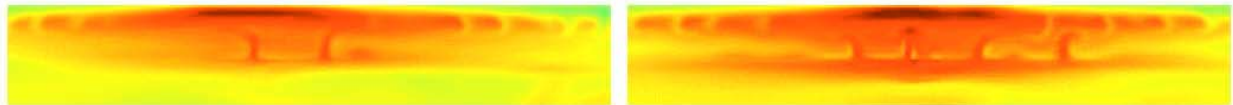

$k=1+10\left(T_{0}+T\right)^{3} \quad$ in $D^{\prime}, \quad k=1$ above $D^{\prime}$

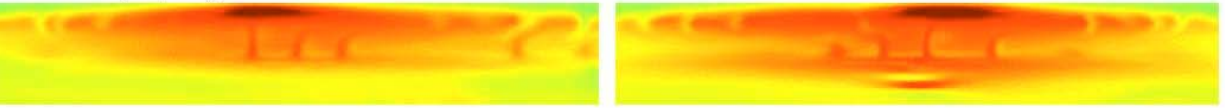

$k=1+10\left(T_{0}+T\right)^{3}$ in the whole mantle

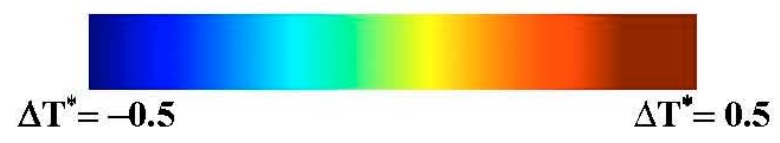

Fig. 15 
New thermal expansivity $P_{670}=-0.08 \quad P_{D}=0.05$

$k=1+10\left(T_{0}+T\right)^{3}$ in D", $k=1$ above D"; time steps $=0.00005$
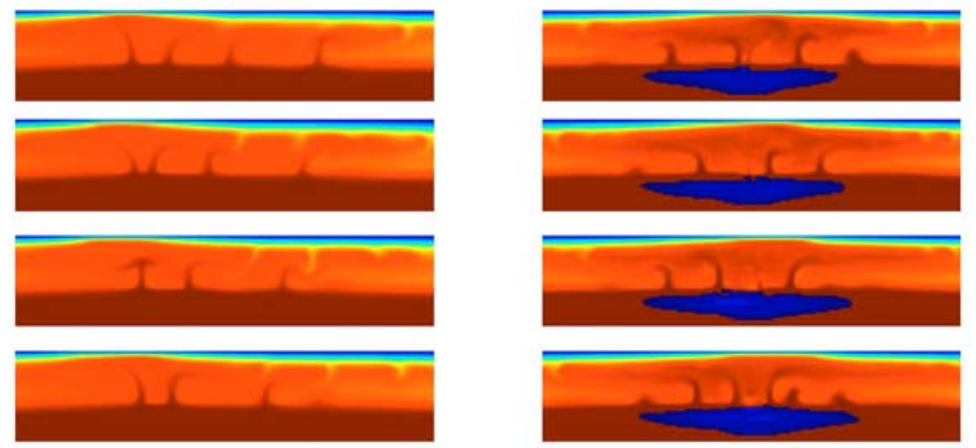

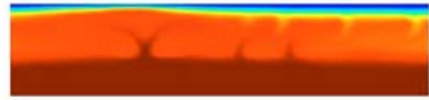
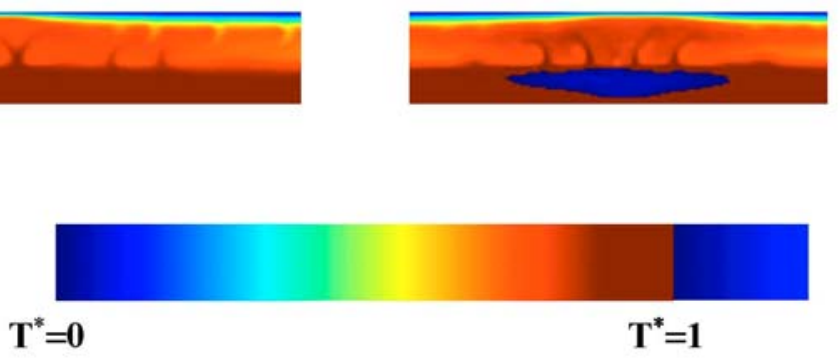

Fig. 16 


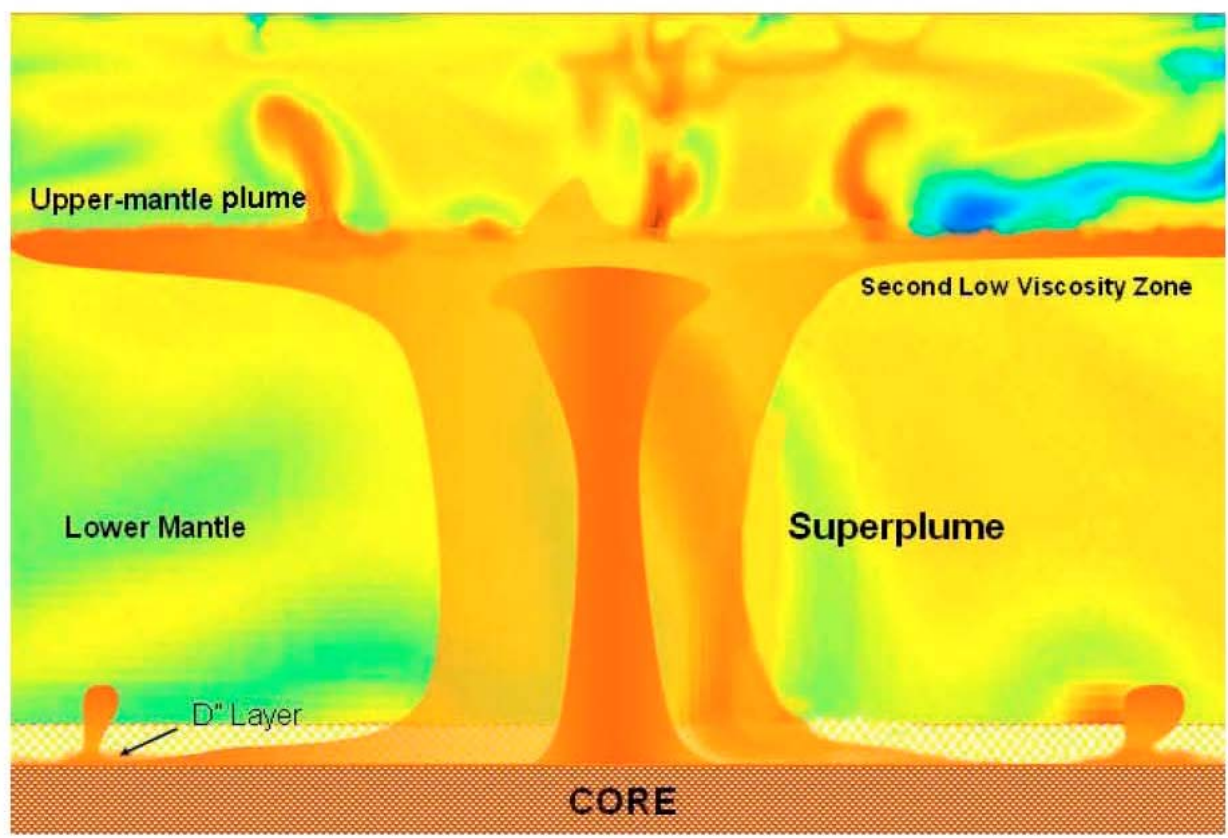

Fig. 17 